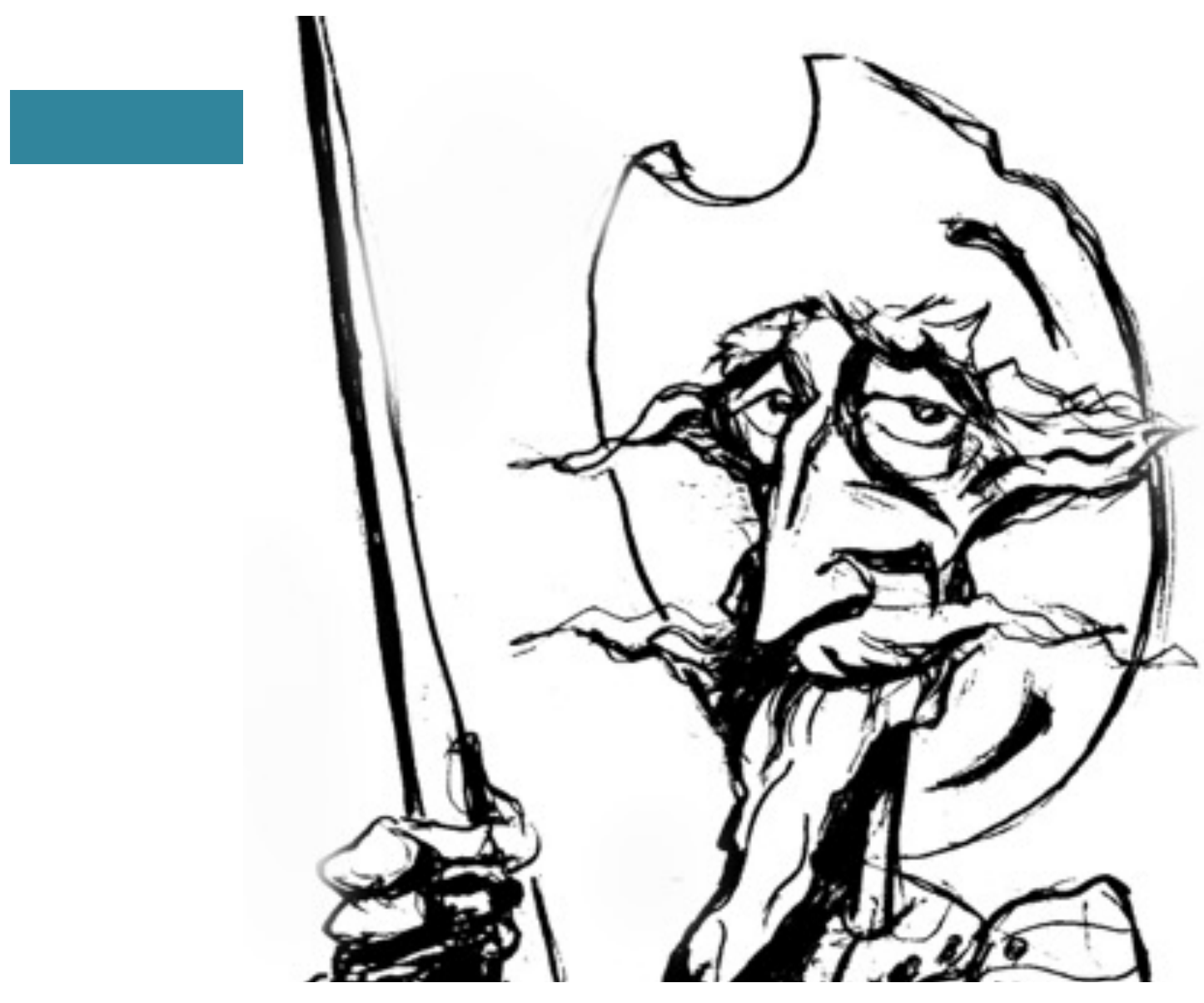

El municipalismo de Ambrosio Funes. Prácticas e ideas acerca de los cabildos rioplatenses en tiempos de crisis: 1805-1809

[Edgardo Dainotto] 


\title{
El municipalismo de Ambrosio Funes. Prácticas e ideas acerca de los cabildos rioplatenses en tiempos de crisis: 1805-1809*
}

\author{
The municipalism of Ambrosio Funes. Practices and Ideas about the Río de la \\ Plata Councils in Times of Crisis: 1805-1809
}

EDGARDO DAINOTTO

\section{Resumen}

El presente trabajo indaga sobre el imaginario político en el Río de la Plata durante las invasiones inglesas y la crisis producida por Napoleón en la Metrópoli española. Se intenta visualizar las redes que sostuvieron los proyectos de autonomía de las colonias respecto de la península, gobernadas por los cabildos de cada jurisdicción. El análisis del desempeño institucional de Ambrosio Funes permite el acceso a un complejo sistema de pensamiento y de acción en el que coexistían la fidelidad a la dinastía con la reformulación del gobierno de los territorios de la monarquía.

\section{Palabras clave}

Cabildos - monarquía - juntas - 1808/1809 - Río de la Plata

\begin{abstract}
This paper researches into the political imaginary involved in the Río de la Plata territory during the English invasions as well as the crisis produced by Napoleon in the Spanish Metropolis. An attempt is made to visualize the networks that sustained the autonomy projects of the colonies from the Peninsula, which were governed by the Cabildo in every jurisdiction. The analysis of the institutional performance of Ambrosio Funes allows access to a complex system of thought and action in which loyalty to the dynasty coexisted with the reformulation of the government of the territories of the monarchy.
\end{abstract}

Key words

Cabildo - Monarchy - Juntas - 1808/1809 - Río de la Plata

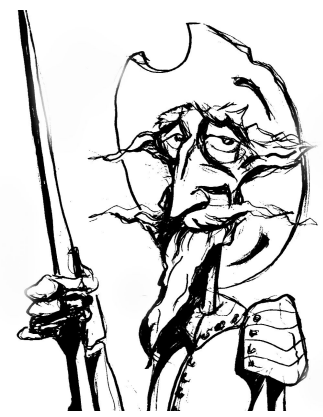

Recibido con pedido de publicación el 25 de abril de 2018

Aceptado para su publicación el 7 de agosto de 2018

Versión definitiva recibida el 21 de octubre de 2018

Edgardo Dainotto, Centro de Investigaciones de la Facultad de Filosofía y Humanidades, Universidad Nacional de Córdoba, Argentina; e-mail: edgardodainotto08@gmail.com

* Agradezco a los evaluadores por sus comentarios y sugerencias

Esta obra se publica bajo licencia Creative Commons. Atribución-NoComercial-CompartirIgual $\underline{4.0 \text { Internacional }}$

Dainotto, Edgardo "El municipalismo de Ambrosio Funes. Prácticas e ideas acerca de los cabildos rioplatenses en tiempos de crisis: 1805-1809", Prohistoria, Año XXI, núm. 30, dic. 2018, pp. 27-69. 


\section{Introducción ${ }^{1}$}

Entre abril de $1808^{2}$ y octubre de $1809^{3}$ el cordobés Ambrosio Funes vivió en Buenos Aires. Quería tomar distancia de las luchas de facciones en su ciudad; allí, los cabildos político ${ }^{4}$ y eclesiástico ${ }^{5}$ estaban en manos de vecinos vinculados al ex gobernador y ex virrey Sobremonte. En Buenos Aires, en cambio, el cabildo seguía conformado por vecinos europeos como Álzaga, ${ }^{6}$ héroe de la reconquista y de la defensa de 1806 y 1807, con quien compartía convicciones sobre cómo debían salir las colonias españolas de las crisis desatadas por Napoleón en la península; ambos, además, se sentían y actuaban como enemigos de Sobremonte a quien la maquinaria capitular de la capital había defenestrado en febrero de 1807 del virreinato. Un marino de carrera como de Elío, gobernador de Montevideo, timoneó desde setiembre de 1808 un proceso autonómico de su élite, enfrentando a Liniers, que era virrey desde mayo de 1807; de Elío era un funcionario peninsular comprometido con fidelizar a los súbditos del monarca preso, frente a la dudosa integridad del virrey de origen francés. De Elío y Álzaga, que actuaban en consonancia contra Liniers, ${ }^{7}$ eran,

1 Este trabajo tuvo origen en un proyecto de tesis desistido, dirigido por Ana Inés Punta, que se denominó: "Los cambios político-institucionales en Córdoba. La transición de jurisdicción colonial a provincia-estado. 1760-1835," presentado en la Universidad Nacional de Córdoba. Agradezco a los colegas que enriquecieron las ideas originarias con sus comentarios: a Sonia Tell, Virginia Ramos, Martín Gentinetta y, en especial, a Ana Inés Punta.

2 Colección de documentos Mons. Pablo Cabrera, Biblioteca de la Facultad de Filosofía y Humanidades, Universidad Nacional de Córdoba, (en adelante CMPC), doc. núm. 6061 (Sobre su ida a Bs As que alguien calificó de huida. Refiérese a su permanencia en la quinta de Álzaga. Pormenores relacionados con la invasión inglesa, mayo de 1810). Agradezco a la colega Virginia Ramos el haberme facilitado las fotografías digitales de los documentos de esta colección.

3 El día 10 de noviembre ya estaba en Córdoba: "Y así estando: se mandó abrir un pliego de S.E. que en este día me entregó don Ambrosio Funes, y se encontró un oficio de 23 de octubre del presente año, en que se encarga no se moleste á dicho don Ambrosio en cosa alguna" (Acta del cabildo de 10 de noviembre de 1809); CABILDO DE CÓRDOBA, Actas capitulares. Libros cuadragésimo tercero y cuadragésimo cuarto, Archivo Histórico Municipal, Córdoba, 1966, pp. 90 y 91.

$4 \quad$ CMPC doc. núm. 6218 (Sucesos relativos al Gob. Int. Gutierrez de la Concha, desde que entró de Gobernador a Córdoba y su Provincia, 1809).

$5 \quad$ Al cabildo eclesiástico lo formaban en estos años cuatro miembros: Juan Justo Rodríguez, Francisco Javier Eusebio de Mendiolaza, Vicente Isasmendi y Gregorio Funes, hermano de Ambrosio (TELL, Sonia Actas del Cabildo Eclesiástico. Obispado del Tucumán con sede en Córdoba [1802-1809], Tomo III, Ferreyra Editor, Córdoba, 2012). Salvo Gregorio Funes, para Ambrosio los otros tres eran adeptos al marqués de Sobremonte; CMPC doc. núm. 5703 (Arbol inficionado de genealogía partidaria..., sin fecha).

$6 \quad$ En particular el cabildo de Buenos Aires era un órgano casi exclusivamente compuesto por europeos: AGN, IX, 26-7-10 (Invasiones Inglesas). También: Mayo documental, VII, doc. núm. 870, p. 204 (Carta y representación de Pedro Baliño de Laya al presidente y vocales de la Junta del Reyno de Galicia..., 21 de enero de 1809)

$7 \quad$ WILLIAMS ÁLZAGA, Enrique Dos revoluciones: $1^{\circ}$ de enero de 1809- 25 de mayo de 1810, Emecé, Buenos Aires, 1963, p.158. 
para Funes, verdaderos servidores de la monarquía, enfrentando a los que ejercían indecentemente -decía él- el gobierno colonial que la corona les había encargado. Liniers, Sobremonte, Gutiérrez de la Concha, los oidores, etc., no eran más que malos mandones que, como su protector Godoy -el ministro español favorito de Carlos IV hasta marzo de 1808- se aprovechaban en su propio beneficio de la situación de la Metrópoli, sometida por Napoleón. ${ }^{8} \mathrm{Y}$ Córdoba era una de esas jurisdicciones presas de los malos servidores del rey cautivo: los sobremontistas.

Durante esa estadía en el puerto, probablemente hacia fines de 1808, produjo Funes un documento en el que vuelca sus expectativas de reformulación del gobierno colonial. Partiendo de un cambio en el estatus de las provincias-intendencias virreinales dentro de la monarquía, proyecta un verdadero protectorado de Buenos Aires sobre ellas, sometidas todas a una distante soberanía borbónica. ${ }^{9}$ La solución juntista ${ }^{10}$ dada por las ciudades y reinos de la península a la crisis de la monarquía católica desde mayo de 1808, era una oportunidad para consolidar los logros obtenidos por la elite de Buenos Aires un par de años antes, gracias a las invasiones inglesas, con ayuda de sectores de las otras ciudades del virreinato. Esta liga de jurisdicciones que proyectaba Funes no haría más que legalizar y ampliar la autonomía defensiva y hacendística de las provincias-intendencias del virreinato como un modo de mantenerlas bajo jurisdicción española, cuando Francia, Inglaterra y Portugal ya no disimulaban su intención de apropiárselas. ${ }^{11}$ De este laxo vínculo políticomercantil que uniría a la Metrópoli con las provincias del virreinato, decía

\footnotetext{
8 CMPC doc. núm. 6249 (Algunos pormenores relacionados con los preludios de las invasiones inglesas, etc., 1810 [?])

$9 \quad$ El texto que trataremos más adelante en detalle (CMPC doc. núm.6252 [Sobre medidas que estimara prudente dictar S.M. atendiendo a las circunstancias del momento]), usa el sustantivo "protección" para definir el vínculo entre capital y ciudades del interior. Verdo propone que la apropiación que el cabildo de Buenos Aires hizo de la "protección a los cabildos del virreinato" en 1807, que luego se expresó metafóricamente como "la hermana mayor" de las provincias, está en la base de las facultades que invocó para tomar las decisiones a nombre de toda la jurisdicción virreinal; VERDO, Geneviève “¿Soberanía del pueblo o soberanía de los pueblos?", en Andes, núm. 13, Salta, 2002, p. 146.

10 LUCENA GIRALDO, Manuel Naciones de rebeldes. Las revoluciones de independencia latinoamericanas, Santillana, Madrid, 2010.

11 Para un repaso breve de las diversas posturas que se sostuvieron en el bienio 1808-1810 ver CHUST, Manuel "El rey para el pueblo, la constitución para la nación", en MINGUEZ, Víctor y CHUST, Manuel (eds.) El imperio sublevado, Universitat Jaume I, Madrid, 2004, pp. 225254.
} 
Funes, el monopolio sería parte esencial, aunque retocado para disminuir su asimetría. $^{12}$

El de Ambrosio fue uno de los proyectos que circulaban entre los grupos que podían participar en la reformulación del vínculo colonial. Era una de las tramas que el imaginario político de la época hacía verosímil y hasta probable. ${ }^{13}$ La verosimilitud del proyecto para su autor, hombre experimentado en lides administrativas locales y regionales, nos da acceso no solo a su subjetividad sino a la red en la que se produjo. ${ }^{14}$ Las soluciones propuestas por Ambrosio hasta el instante previo a conocerse en Córdoba la creación de la Junta de mayo de 1810 de Buenos Aires, ${ }^{15}$ pretendían remodelar los vínculos entre las provincias coloniales y la Metrópoli, pero dejando siempre a salvo la soberanía regia. Su posición le permitía manifestarse a favor de acciones como las que desplegaban Martín de Álzaga, que pretendía reformas más profundas que la mera reconfiguración del vínculo entre Metrópoli y colonias; ${ }^{16}$ o como las de Elío, que solo buscaba moralizar la función gubernamental erradicando el estilo y las redes impuestas por Godoy y sus seguidores. ${ }^{17}$ Analizar los conceptos utilizados por el cordobés y su acción político-administrativa en el contexto de

12 Un repaso historiográfico sobre la composición interna de esta asimetría en: SCHLEZ, Mariano Dios, rey y monopolio: los comerciantes monopolistas y la contrarrevolución en el Río de la Plata tardo colonial, RyR, Buenos Aires, 2010, pp. 17-63.

13 QUIJADA, Mónica "La potestas populi: una revisión del pensamiento hispánico y la modernidad", en BRAGONI, Beatriz y MATA, Sara (comps.) Entre la Colonia y la República. Insurgencias, rebeliones y cultura política en América del Sur, Prometeo, Buenos Aires, 2008, pp. 2950. En la p. 32 especifica que "los elementos que contribuyen a configurar un imaginario político son múltiples, desde la acción práctica, incluida la violencia, hasta las teorías más refinadas". En la Metrópoli, los proyectos para flexibilizar el vínculo colonial y así evitar el quiebre de la monarquía católica fueron varios durante la época que estudiamos; ver la nota núm. 7 .

14 RICOEUR, Paul "La acción considerada como un texto", en Hermenéutica y acción. De la hermenéutica del texto a la hermenéutica de la acción, Editorial Docencia, Buenos Aires, 1988, pp. 4774; IMÍZCOZ BEÚNZA, José María "Por una historia conectada. Aplicaciones del análisis relacional" y "La clase política del reformismo borbónico: las redes sociales del cambio", ambos en Magallánica, Revista de Historia Moderna, Julio-diciembre, 2017, pp. 1-9 y 10-62, respectivamente. En línea: file:///D:/Downloads/2604-7961-1-PB.pdf

15 En una carta fechada en Córdoba, en 17 de mayo de 1810, dirigida al cabildo de Buenos Aires, Funes reiteraba su fidelidad al monarca cautivo y ofrecía un donativo para sostener la causa; ver CMPC doc. núm.5694 bis (Sobre contribución a favor de "las urgencias de esa capital").

16 Una "república independiente en manos españolas", según WILLIAMS ÁLZAGA, Enrique Dos revoluciones..., cit., p. 121. Saavedra dice "otra España americana"; SAAVEDRA, Cornelio Memoria Autógrafa, Editorial del Nuevo Extremo, Buenos Aires, 2009, p. 44.

17 CMPC doc. núm. 6249, cit. En cita de WILLIAMS ÁLZAGA, dice Presas, secretario privado de la princesa Carlota: "Hasta entonces los americanos y europeos no había experimentado los efectos del despotismo. El gobierno absoluto de la metrópoli y la corrupción y venalidad de sus mandatarios [refiriéndose a Godoy] hostigaron a los americanos para declararse independientes"; WILLIAMS ÁLZAGA, Enrique Dos revoluciones..., cit., p. 64. 
las personas que lo consideraban su aliado, nos permite visualizar una identidad política $^{18}$ constituida con posiciones compatibles parcial y provisoriamente, pero unidas por su común voluntad de incidir en el ejercicio de la autoridad. Para nosotros, la revolución (de entre las distintas alteraciones políticas posibles) fue una de las salidas que se tuvieron en cuenta; hubo otras que quedaron en el camino pero que para sectores sociales relevantes fueron opciones ciertas, al menos durante un tiempo. ${ }^{19}$ En esa línea de análisis abordamos la acción y las ideas de Ambrosio Funes en dos tramos sucesivos de su trayectoria pública, articuladas por el acaecimiento de las invasiones inglesas de 1806 y 1807. No es un intento de adscribir a Ambrosio en alguna corriente ideológica o de teoría política o filosófica; sí es un estudio de sus acciones en ámbitos del gobierno y de la administración, y de las ideas que compartía con otros grupos o individuos. Funes, Álzaga y de Elío aprovecharon a los cabildos en la definición de posiciones políticas. Los ayuntamientos de Córdoba, Buenos Aires, Montevideo, bajo la influencia o la dirección de aquellos, se involucraron en temas que habitualmente estaban fuera de sus competencias, porque la permanente situación de guerras que caracterizó a España durante más una década -al menos desde 1790-, puso a los ayuntamientos en el centro de la escena. Como señala Chiaramonte, ${ }^{20}$ estas instituciones tenían las herramientas para controlar las situaciones locales y regionales; la guerra hacía probables la incomunicación con las autoridades metropolitanas $\mathrm{o}$, directamente, su desaparición. Frente a ello, se creía, podrían pilotearse desde los cabildos las posibles vacancias y la desarticulación que se avizoraban. Así, se convirtieron en el botín deseado por todas las facciones, pues serían naturalmente los ámbitos de redefinición política en tiempos de crisis. Llamamos municipalismo al conjunto de premisas ideológicas, jurídicas y prácticas que proponía colocar a los órganos institucionales vecinales -los cabildos-, como máximas autoridades locales y articuladores principales de la relación corona-vasallos, en desmedro de los recursos institucionales que habían sido creados durante el reinado de

\footnotetext{
18 Mata describe a la identidad política como "un sentido de pertenencia a un grupo con aspiraciones concretas de poder, portador de un proyecto político de organización de la comunidad"; MATA, Sara Emilia "Construyendo identidades: la guerra de independencia en los Andes del Sur", en AMADORI, Arrigo y DI PASQUALE, Mariano Construcciones identitarias en el Río del a Plata, siglos XVIII-XIX, Prohistoria Ediciones, Rosario, 2013, pp. 41-58; la cita es de p. 46.

19 Dice Gelman respecto de la revolución de mayo de 1810: “Pero ese resultado no era inevitable, y esta perspectiva nos muestra que en casi cada uno de los caminos emprendidos había alternativas que eventualmente podían seguirse"; GELMAN, Jorge "Las claves del periodo", en Argentina. Crisis imperial e independencia, I, Fundación Mapfre, Lima, 2010; pp. 2349.

20 CHIARAMONTE, José Carlos Ciudades, provincias, Estados: Orígenes de la Nación Argentina (1800-1846), Emecé Editores, Buenos Aires, 2007, p. 95.
} 
Carlos III (las intendencias de provincia, por ejemplo); ${ }^{21}$ intentaremos justificar esta posición a lo largo del trabajo. Con estas herramientas municipalistas, durante ese periodo de coincidencias, los tres fueron capaces de condicionar a los agentes de la corona en las jurisdicciones donde residían-Córdoba, Buenos Aires y Montevideo- hasta mediados de 1809.22

\section{La contrarrevolución cordobesa: un escollo interpretativo}

Un problema significativo para el estudio de las identidades políticas anteriores a la revolución de 1810, es que fueron absorbidas por la revolución, como si todo lo anterior a Mayo hubiera estado premeditadamente orientado a su realización. La contrarrevolución de las principales instituciones cordobesas, en agosto de 1810, es leída en clave de simple anomalía sujeta a rectificación; así, desaparecen todas las opciones que se barajaron en su oportunidad y la de los procesos de oposición por no encuadrar entre los hechos que favorecieron la revolución. Estos relatos han respondido a estructuras narrativas que determinan de antemano el desarrollo y la interpretación de los hechos; son relatos de resultados previsibles e inexorables: tanto la revolución como su contrarrevolución debían producirse. Un buen ejemplo es la interpretación del mismo Ambrosio Funes, quien dijo que a los que fueron fusilados en Cabeza de Tigre, " la fuerza del hado los arrastraba á su última catástrofe". Otros esquemas similares presentan Paul Groussac y Martínez Paz, por mencionar los que se expresan con mayor dramatismo. ${ }^{23}$ Esta interpretación permitía dejar a salvo el honor de los contrarrevolucionarios explicando sus conductas por factores ineludibles, y justificar la tardía incorporación de buena parte de la elite cordobesa a la revolución porteña con un planteo naturalista de maduración lenta y diferenciada de las ideas de emancipación, según fueran en la capital o en las provincias. ${ }^{24}$ A pesar de sus debilidades, tal narración tiene la ventaja de

$21 \quad$ Mitre lo llamó "la teoría de la soberanía municipal”; MITRE, Bartolomé Comprobaciones históricas: a propósito de algunos puntos de historia argentina segun nuevos documentos, Volumen 1, Imprenta y Librería de Mayo, Buenos Aires, 1882; p. 254.

22 CMPC doc. núm. 6249, cit. Para una interpretación de Godoy integrada a la crisis producida por la revolución en Francia, ver RODRÍGUEZ, Jaime La independencia de la América española, Fondo de Cultura Económica, México, 1996, pp. 70 y ss.

23 FUNES, Ambrosio "Relación de los sucesos de Córdoba procedentes del nuevo Gobierno que estableció la Capital de Buenos Aires en [25 de Mayo] de 1810", transcripto en LUQUE COLOMBRES, Carlos "El Doctor Victorino Rodríguez. Primer catedrático de Instituta en la Universidad de Córdoba. Apéndice documental", en Para la historia de Córdoba, Biffignandi Ediciones, Córdoba, 1973 [1947], pp. 446-452; MARTÍNEZ PAZ, Enrique La formación histórica de Provincia de Córdoba, Imprenta de la Universidad. Córdoba, 1941, p. 25; GROUSSAC, Paul Santiago de Liniers, Editorial Estrada, Buenos Aires, 1965; pp. 358 y ss.

24 Un ejemplo claro es Zinny, que diferenciaba la reacción institucional de la de los individuos: "El deán era agente oculto de la revolución en esa ciudad"; "Existía en la ciudad un ardiente 
reflejar la coexistencia en Córdoba de fenómenos de adhesión y de rechazo a los cambios en la relación del virreinato con la monarquía, alejando el riesgo de identificar a toda la sociedad cordobesa con la contrarrevolución. No obstante, aunque se aceptase esquematizar la situación de Córdoba a mayo de 1810 como de instituciones políticas contrarrevolucionarias y grupos locales ocultamente revolucionarios, y aunque se pudiera compensar ideológicamente la contrarrevolución institucional con una revolución social latente, sigue siendo legítimo pensar la primera década del siglo XIX sin tener a la vista el triunfo de la revolución. Es decir, interesarse por cómo actuaron hasta mayo de 1810 los grupos y las instituciones de Córdoba, sin ponderarlos por lo que ocurrió luego de mayo de 1810. En nuestro trabajo intentamos analizar la reacción de una facción de la elite cordobesa frente a la crisis monárquica de 1808 hasta antes de la llegada de la noticia de la caída de Cádiz a manos napoleónicas, en mayo de 1810; un relato que considere los hechos desde la perspectiva del régimen imperial en crisis y no desde los logros y las valoraciones de la sublevación independentista posterior.

Hay aportes historiográficos recientes sobre la sociedad y las instituciones de la jurisdicción cordobesa que van en esta dirección, y que permiten analizar el periodo previo a la revolución como epílogo de un largo siglo XVIII borbónico. En especial los trabajos de Ayrolo y Ramos hicieron aportes conceptuales a la cuestión, al situar los hechos en el horizonte de la crisis de la Monarquía Hispánica. Ayrolo ${ }^{25}$ plantea la existencia de una única elite virreinal, fraccionada internamente no tanto por su localización o jurisdicción de pertenencia, sino por las diversas posiciones que podían asumirse sobre la situación de la monarquía. Esta es una afirmación potente y sugestiva que, aunque esté todavía sujeta a validación, obliga a dirigir la atención hacia las redes que anudaban grupos de las elites municipales entre sí, trascendiendo los límites de su ámbito de acción cotidiano a través de la

fuego revolucionario, aunque artificiosamente encubierto"; ZINNY, Antonio Historia de los gobernadores de las provincias argentinas, II, Hyspamerica, Buenos Aires, 1987, p. 228. Siendo clara la reacción fidelista de las instituciones cordobesas, solo quedaba rastrear en la elite a revolucionarios muy cautelosos, como el deán Funes. El testimonio de Fernando de Abascal, el virrey peruano que desde 1806 hasta 1816 fue alma de las posiciones realistas, la llama "la traidora Córdoba" (ABASCAL, José Fernando Memoria de gobierno del Virrey Abascal: 1806-1816, Escuela de Estudios Hispanoamericanos, I, Sevilla, 1944, p. 292), también "viles cordobeses" (Archivo General de Indias [en adelante AGI], Diversos, Legajo núm. 1, Año 1810, Ramo 214/1012), por no sostener estos la guerra iniciada por Liniers y Concha contra la "insurrecta Buenos Aires".

25 AYROLO, Valentina "La ciudad cooptada. Refractarios y revolucionarios en Córdoba del Tucumán (1810-1816), en Anuario IEHS, vol. 26, Tandil, 2011, pp. 11-29; cita de la p. 8. 
adhesión a identidades políticas con presencia en varias jurisdicciones. Ramos, ${ }^{26}$ por su lado, resaltó la incidencia de los factores internacionales en las posiciones locales asumidas frente a la crisis dinástica; sus estudios permiten insertar las decisiones políticas locales como piezas pequeñas de un tablero de dimensiones imperiales. Otra interpretación que interesa a los fines de construir una historia que no esté arrastrada por el futuro ya conocido es la de Moutoukias y Amaral, ${ }^{27}$ que reflexionan sobre la actividad comercial y fiscal en Buenos Aires, durante la misma etapa (1809). Hacen notar cómo las facciones de la elite ensayaron múltiples proyectos para frenar o acelerar las tendencias de larga duración ante las violentas coyunturas suscitadas por las guerras europeas; tales intervenciones generaban un proceso de final abierto.

En conjunto, estas sugerencias constituyen intereses y métodos renovados que ayudan hoy a avanzar sobre tópicos muy abordados por la historiografía, pero con la posibilidad de dar cuenta de la multiplicidad de opciones y condicionantes que los actores del momento debieron considerar. Se trata de percibir la complejidad de aquella etapa a través de la multiplicidad de opciones disponibles. ${ }^{28}$

\section{La gobernación intendencia de Córdoba del Tucumán a inicios del siglo XIX}

La crisis de la monarquía española suscitada por Napoleón desde fines de 1807 es una etapa a la que el cabildo ${ }^{29}$ y la gobernación intendencia ${ }^{30}$ de Córdoba llegaron como unas instituciones en transformación. Ambas, a pesar de representar distintos intereses y manejarse con plexos normativos diversos, ${ }^{31}$ habían atravesado un periodo de fuerte presión ejercida por la Metrópoli para

26 RAMOS, María Virginia Procesos políticos en Córdoba hacia fines de la colonia y comienzos del periodo revolucionario: tensiones y conflictos entre los grupos de poder, Trabajo final de licenciatura, Universidad Nacional de Córdoba, inédito, 2012.

27 MOUTOUKÍAS, Zacarías y AMARAL, Samuel “Las tramas de la acción política: crisis fiscal, tolerancia comercial y construcción institucional (Buenos Aires, 1809)", en Anuarios IEHS, vol. 25, 2010, pp. 97-117.

28 GELMAN, Jorge "Las claves...", cit.

29 PUNTA, Ana Inés Córdoba borbónica. Persistencias coloniales en tiempo de reformas (17501800). Universidad Nacional de Córdoba, Córdoba, 1997; ver especialmente las Conclusiones, pp. 226 y ss.

30 RAMOS, María Virginia Procesos políticos en Córdoba..., cit.

$31 \quad$ Postulamos la vigencia de dos tradiciones jurídicas legítimas en la construcción política local durante las reformas de Carlos III: la tradición regia y la capitular. La primera emanaba de la corona y se orientaba a afianzar su predominio sobre las otras jurisdicciones, en especial la capitular o municipal. A esta la defendían principalmente las oligarquías locales como factor de limitación al avance de las prerrogativas monárquicas y la de sus agentes; DAINOTTO, Edgardo Política y poder en Córdoba borbónica. Instituciones, espacios y prácticas (1783-1797), Ediciones Ferreyra, Córdoba, 2012. 
optimizar los rendimientos en su beneficio de la exacción colonial y fortalecer la exclusividad de la jurisdicción monárquica, en especial durante el reinado de Carlos III (1760-1788); la política local fue embargada con muchas medidas que priorizaban los intereses de los agentes metropolitanos residentes en la jurisdicción. ${ }^{32}$ Por mencionar las más relevantes para el ámbito de Córdoba, comenzamos con la expulsión de los jesuitas en 1767, a los que esta ciudad había hospedado desde inicios del siglo XVII. Allí operó un complejo académico y comercial de notable envergadura regional, cuyo funcionamiento estaba imbricado con la sociedad cordobesa con sólidos vínculos simbólicos y económicos. ${ }^{33}$ Otra fue la reconfiguración del poder institucional local, por la que la Metrópoli buscaba disciplinar a las elites locales forzando desde la audiencia de Charcas y la gobernación -con sede en Salta hasta 1783- la incorporación al cabildo local ${ }^{34}$ de inmigrantes europeos recientes, a veces de escaso caudal y siempre con mucho menos arraigo que los patricios (descendientes ciertos o supuestos de fundadores y conquistadores); estos son los que tradicionalmente habían ocupado los cargos capitulares. ${ }^{35}$ Dentro del mismo conjunto de medidas de la década de 1760, resaltamos los ajustes que impulsó la gobernación del Tucumán sobre la tributación que gravaba el comercio, en particular la sisa, y reorientación del gasto de esos fondos, que

32 Punta sugiere que el incremento recaudatorio se derramó en la misma jurisdicción, bajo la forma de salarios administrativos, gastos militares, etc., sin beneficiar a la metrópoli en sí. PUNTA, Ana Inés Córdoba borbónica..., cit., pp. 226 y ss. En el mismo sentido, Schlez recupera la hipótesis de que los estudios sobre la estructura burocrática imperial rioplatense permiten afirmar "que, aunque se financiaban con recursos americanos, el costo de mantener a jueces, administradores, militares y religiosos, le era indispensable a la Corona para garantizar el flujo de riquezas dirigido a España"; SCHLEZ, Mariano Dios, rey y monopolio..., cit., p. 35.

33 ARCONDO, Aníbal El ocaso de una sociedad estamental. Córdoba entre 1700 y 1760, Universidad Nacional de Córdoba, Córdoba, 1992, pp. 261 y ss.; LORANDI, Ana María Poder central, poder local. Funcionarios borbónicos en el Tucumán colonial. Un estudio de antropología política, Prometeo, Buenos Aires, 2008, pp.157 y ss.

34 PUNTA, Ana Inés "El Cabildo de Córdoba del Tucumán: su conformación, políticas y conflictos en el siglo XVIII", ponencia presentada en XVI Congreso de la Asociación de Historiadores Latinoamericanistas europeos, (AHILA) Cádiz, 2011.

$35 \quad$ "Patricios y europeos" es el binomio con que los documentos de la época designaban a los descendientes -ciertos o pretendidos- de los conquistadores y fundadores, y a los llegados durante los siglos XVIII y XIX, respectivamente; ver la Relación de los sucesos de Córdoba procedentes del nuevo gobierno que estableció la Capital de Buenos Aires en 1810, transcripta parcialmente en el apéndice documental de "El Doctor Victorino Rodríguez...", cit., pp. 446-452. La genealogía capta la presencia y estrategias de estos grupos de europeos llegados en la primera mitad del siglo XVIII; pp. 347 y ss. Arcondo llama "parvenus" (advenedizos, en francés) a los europeos llegados entonces: ARCONDO, Anibal El ocaso de una sociedad estamental..., cit., pp. 265 y ss. Lorandi hace notar los problemas de identidad social que acarreaba esta presencia de peninsulares en la década de 1760 en LORANDI, Ana María Poder central..., cit., p. 80. Cornelio Saavedra usa este binomio en sus memorias; SAAVEDRA, Cornelio Memoria Autógrafa..., cit., p. 43. 
hasta entonces habían manejado los cabildos de la provincia como componente de sus ingresos propios, cuando hubiera correspondido destinarlos íntegramente a la frontera. ${ }^{36}$

Otro conjunto de decisiones estuvo constituido por las reformas más emblemáticas y mejor conocidas de Carlos III: la creación del virreinato del Río de la Plata en 1776-1777 y su división interna en Intendencias de Provincias en 1782 (instrumentada en Real Ordenanza de Intendentes y alguna real cédula modificatoria al año siguiente). Por ellas, la jurisdicción cordobesa había pasado a ser sede de una gobernación intendencia; su titular, el gobernador intendente, estaba dotado de un gran poder de intervención en asuntos que antes solo había manejado la elite capitular; era el ejecutor de las reformas hacendísticas, administrativas y militares de Carlos III, y su razón de ser era, en parte, extinguir o acotar los poderes municipales. ${ }^{37}$ Más coyunturalmente, algunas medidas sobre el comercio tomadas en la Metrópoli o por sus agentes de mayor jerarquía en el puerto alteraba los equilibrios internos en estas jurisdicciones: el debilitamiento del monopolio, que impactaba generando atajos para algunos grupos para posicionarse en la sociedad, y obstáculos para otros para mantenerse en la cima. ${ }^{38}$

Estos hechos obligaron a las elites locales a sumarse a nuevas prácticas políticas para seguir teniendo un lugar protagónico en sus medios. Los enfrentamientos entre quienes se vieron beneficiados por estos cambios y quienes lo padecieron tanto en lo político-simbólico como en lo económico, constituyen el horizonte de interpretación común para las acciones políticas del último lustro colonial, al menos en Córdoba del Tucumán. ${ }^{39}$

\footnotetext{
36 El golpe era doble: quitar fondos al ayuntamiento y recuperar el control de la frontera, por donde también pasaba el contrabando; LORANDI, Ana María Poder central..., cit. Sobre el mal uso de los producido por la sisa, GULLÓN ABAO, Alberto José La frontera del Chaco en la Gobernación del Tucumán, 1750-1810, Universidad de Cádiz, Cádiz, 1993. En el mismo sentido se expresa VITAR, Beatriz Guerras y misiones en la frontera chaqueña del Tucumán (1700-1767), Consejo Superior de Investigaciones Científicas, Madrid, 1997. El texto del reglamento de 1766 en: PUNTA, Ana Inés y RUSTÁN, María Elizabeth (comps.) Córdoba borbónica a través de sus documentos..., cit., pp. 161-180.

37 DAINOTTO, Edgardo Poder y política..., cit., pp. 103 y ss.

38 SEGRETI, Carlos S.A. Temas de historia colonial (Comercio e injerencia extranjera), Academia Nacional de la Historia, Buenos Aires, 1987; SCHLEZ, Mariano Dios, rey y monopolio..., cit.

39 Esta es una línea estructural y de larga duración en la explicación de la etapa final de la colonia. Gelman habla de factores endógenos para designar este tipo de condicionantes. Llama exógenos a los que irrumpieron en razón de la situación europea; GELMAN, Jorge "Las claves...", cit., p. 31.
} 


\section{Ambrosio Funes}

Ambrosio Funes pertenecía a una familia asentada en Córdoba desde la fundación; ${ }^{40}$ nació y murió allí en 1753 y 1826, respectivamente. ${ }^{41}$ En términos de su época, era un patricio. Su actividad pública se inicia a fines de 1770 y se extiende por casi cuatro décadas. Fue “...tres o quatro años el primer magistrado de este Ayuntamiento: en otro de primer Diputado de Comercio, dos de Síndico Procurador y cerca de veinte ha mandado su Regimiento de Milicias Urbanas ó provinciales...";42 era hombre de muchas lecturas, comerciante con vasto giro de mulas a fines del siglo XVIII, ${ }^{43}$ pero también varios fracasos en el XIX.44 Para un observador extranjero, Ambrosio Funes era un "hacendado, natural de Cordova". ${ }^{45}$

Las milicias constituyen un eje de su historia personal. ${ }^{46}$ Ambrosio fue desde 1777, aproximadamente, fundador y sargento mayor del regimiento de caballería de las milicias urbanas, con nombramiento refrendado posteriormente en varias ocasiones; en él servía a su costa. El contexto de esta inserción en las milicias fue la creación del virreinato del Río de la Plata en 1776-1777, es decir en medio de un proceso de reformulación de vínculos dentro del nuevo espacio político. Los comandantes sucesivos lo mantuvieron en ese cargo de sargento mayor; aunque aspiró en 1798 a acceder a la comandancia del regimiento, le fue otorgada a Santiago Alejo de Allende. ${ }^{47}$ Habría participado en una entrada a la zona del Río Cuarto, contra los indios, y en dos expediciones a Buenos Aires. Las certificaciones de servicio lo hacen ver

40 LUQUE COLOMBRES, Carlos El Deán doctor don Gregorio Funes. Arraigo de su familia en América. Imprenta de la Universidad, Córdoba, 1943, pp. 283-343.

41 MARTÍNEZ PAZ, Enrique La formación histórica..., cit., pp. 48 y 49, a pie de página.

$42 \quad$ CMPC doc. núm. 6234 (Exposicion a favor del Dr Gregorio y de Ambrosio Funes, sus deudos, y en su contra del Gobernador Intendente de Córdoba Gutierrez de la Concha y el círculo de éste en Córdoba..., 4 de junio de 1808). Ver también el certificado expedido por el cabildo de Buenos Aires en 1809, CMPC doc. núm. 5692 ([Ambrosio Funes al Cabildo de Buenos Aires] Solicita la certificación que sigue sobre sus servicios).

$43 \quad$ CMPC doc. núm. 5975 (Informe relacionado con asuntos del Cabildo. Sobre partido formado por Juan Luis de Aguirre. Aluden a la influencia de Ambrosio y Gregorio Funes, que estiman puede resultar excesiva por afectar diversos órdenes y concentrarse en una sola familia, etc., 1797)

44 HALPERIN DONGHI, Tulio Revolución y guerra. Formación de una élite dirigente en la Argentina criolla. Siglo XXI, Buenos Aires, [1972] 1994. Ver pp. 265 y 266. CMPC doc. núm. 5975, cit; MARTÍNEZ PAZ, Enrique Papeles de don Ambrosio Funes, R. Cubas, Córdoba, 1918, p. 513 (Carta de Francisco Letamendi a Ambrosio Funes, 8 de enero de 1808).

45 Mayo documental, IV, doc. núm. 499, p. 196 (Carta de Felipe Contucci dirigida a Rodrigo de Sousa Coutinho..., 16 de noviembre de 1808).

$46 \quad$ CMPC doc. núm. 6221 (Sobre el Coronel Allende y algo respecto a una considerable porción de las principales figuras del circulo adicto a Sobremonte..., 1807)

$47 \quad$ CMPC doc. núm. 5788 (Solicita [al comandante general de la provincia] se le expida el informe que sigue sobre su conducta, cualidades y servicios, 11 de agosto de 1801). 
no solo como un buen soldado del rey, sino como un miembro de la Iglesia preocupado por imponer la moral católica: hombre de "inflexible integridad", esmerado "por contener la relajación de costumbres". También al cumplimiento del culto destinaba sumas importantes, financiando capillas y altares de los principales templos de la ciudad; en su propia opinión, escribiendo en tercera persona, eran obras que mostraban "su inteligencia en las vellas Artes, cooperando asi á los recientes progresos facultativos del buen gusto que se va introduciendo en esta Ciudad". ${ }^{48}$ Reforzaba esta vinculación con lo religioso siendo síndico del monasterio de Santa Catalina; es decir, era el responsable de la administración de sus bienes, de proveer lo necesario para el funcionamiento del mismo y de representar a las monjas en el mundo judicial y administrativo. La demanda de tiempo de esta actividad era significativa y lleva a sus opositores a considerar como incompatibles esa función con la de cabildante. ${ }^{49}$

Su primera incursión en el cabildo fue como alcalde de segundo voto en 1782; es el año anterior al de la llegada de Sobremonte a Córdoba; allí debía residir el marqués como primer titular de la gobernación-intendencia de Córdoba del Tucumán. Ambrosio recién pudo acceder de nuevo a una alcaldía de primer voto en 1797, que fue el último año de Sobremonte en Córdoba. ${ }^{50}$ Durante esa larga década intermedia solo pudo ejercer en 1791 la procuración del cabildo; la facción monárquica sobremontista no lo tuvo en cuenta para esos cargos ni para los de la incipiente burocracia de la intendencia, a través de los cuales se participaba de la mayor exacción que se logró con las reformas administrativas. ${ }^{51}$ Salvo su actuación como rematador del diezmo en algunos años, no se percibe que haya estado en funciones de intendencia que lo habilitaran a recibir de la hacienda real un salario, o premio, o remuneración. ${ }^{52}$

En simultáneo a su condición de oficial de milicias, también en 1795,53 Funes aparece como diputado o juez del Consulado de Buenos Aires, creado el año anterior; las funciones eran principalmente la de juzgar las contiendas entre comerciantes, producir informes sobre la circulación y venta de efectos, y garantizar el desplazamiento de los situados bajados desde el Potosí. ${ }^{44}$ Nótese que este era un cargo designado por el virrey, sobre el cual Sobremonte, que

\footnotetext{
$48 \quad$ CMPC doc. núm. 5788, cit.

$49 \quad$ CMPC doc. núm. 5975, cit.

50 PUNTA, Ana Inés y RUSTÁN, María Elizabeth (compiladoras) Córdoba borbónica a través de sus documentos, Ferreyra Editor, Córdoba, 2014, p. 208 (Autoridades de Cabildo).

$51 \quad$ PUNTA, Ana Inés Córdoba borbónica..., cit.,p. 149.

52 PUNTA, Ana Inés Córdoba borbónica..., cit., p. 111.

53 AGN, IX, 4-6-6 (Consulado,1794-1810).

54 AGN, IX, 4-6-6, cit. Ver: RODRIGUEZ, Benjamín “Una justicia no tan lejana: los comerciantes y el tribunal del Consulado de Buenos Aires, entre su fundación y los primeros años independientes", en Revista de Historia del derecho, núm. 47, Buenos Aires ene/jun. 2014, pp. 149-170.
} 
entonces era el gobernador intendente, no parece tener ninguna injerencia. ${ }^{55}$ En esa tarea muestra su convencimiento de que las viejas fronteras con los nativos no sometidos, afianzadas a desde mediados del siglo XVIII, no debían modificarse, mucho menos a expensas del pueblo, ${ }^{56}$ que es lo que se le achacaba a Sobremonte cuando exigía a los comerciantes y chacareros servicios de chasques o de guardias en las fronteras para ampliar los territorios efectivamente sometidos a la corona. Esto le parecía a Funes una veleidad del marqués que nada agregaba a la circulación de manufacturas y ganados que, por otros medios, ya estaba garantizada desde hacía décadas. ${ }^{57}$

Como dijimos antes, recién durante el último año de la estadía del marqués en Córdoba -1797-, Funes volvió al cabildo como alcalde, ocupando la alcaldía de primer voto; por problemas que él mismo suscitó al impugnar las intromisiones de la intendencia en el funcionamiento del ayuntamiento, ${ }^{58}$ se mantuvo en el cargo nueve meses del año siguiente, de manera interina. Puede decirse que la actividad pública de Ambrosio Funes tomó impulso cuando Sobremonte se retiró de Córdoba. Desde las elecciones del cabildo de 1797, entonces, su intervención pasa a ser múltiple y febril, desarrollando una estrategia de resistencia y confrontación hacia las medidas de centralización de Carlos III y Carlos IV en la versión de Sobremonte. ${ }^{59}$

Apenas abandonó la alcaldía en el año 1798, se enfocó en un aspecto frágil la administración de Sobremonte: las finanzas y la enseñanza en el colegio de Monserrat y en la Universidad. Ambas instituciones, luego de la expulsión de los jesuitas en 1767, habían pasado a manos de los frailes franciscanos; estos

55 AGN, IX, 4-6-6, cit. Durante esta diputación, los escritos de Funes presentan un concepto paternalista de la acción de la ley, como resultado de una actividad social elevadísima. $\mathrm{Su}$ fe en la fuerza de las normas es candorosa, al igual que su confianza en la circulación mercantil como vía de civilización y progreso.

56 El sentido que este término alcanza en los escritos de Ambrosio es preciso: es el sector que se autodenomina español, representado por el cabildo de cada jurisdicción, y que legitima su participación en la exacción colonial diferenciándose de los esclavos y los indios. GELMAN, Jorge "Las claves...", cit., pp. 38 y ss. Para Verdo, pueblos son "las comunidades humanas y políticas que forman las ciudades"; VERDO, Geneviève "El precio del poder: formas y usos políticos de la representación en la independencia argentina (1810-1821)", en Revista de Indias, vol. LXII, núm. 225, 2002, pp. 385-408. Cita de la p. 389.

57 AGN, IX, 4-6-6 (Consulado, 1794-1810). Ver PUNTA, Ana Inés Córdoba borbónica..., cit., p. 219.

$58 \quad$ CMPC doc. núm. 5878 (Testimonio de los acuerdos y demás actuaciones practicadas en las nuevas elecciones de oficios concejiles del año 1798, 25 de agosto de 1798).

59 En la década de 1760, durante la gobernación de Fernández Campero en el Tucumán, algunos capitulares de Córdoba encabezados por Bárcena, montaron junto a facciones de la elite de las otras ciudades, una maquinaria de obstrucción a la apropiación de la sisa por parte del gobernador (ver nota núm. 34) y a la incorporación al cabildo de europeos. LORANDI, Ana María, Poder central..., cit. Ver también PUNTA, Ana Inés "El Cabildo de Córdoba del Tucumán...", cit. 
eran considerados por Funes como aliados de Sobremonte, por su notable apego al regalismo borbónico. ${ }^{60}$ Desarrolló entonces, junto a su hermano el cura Gregorio, canónigo de la catedral cordobesa, una persistente campaña para que el Monserrat y la Universidad quedaran en manos del clero secular, es decir el clero local, y dependientes del obispo ${ }^{61}$ (cargo al que Gregorio aspiró sin éxito por su condición de criollo). ${ }^{62}$

En 1800, Ambrosio intervino en la revisión de la fundación de la Villa del Rosario, que se había formalizado en 1795. Los indios asentados en el paraje de Los Ranchos, lugar donde el marqués la había fundado, argumentaban que él había ignorado la posesión y privilegios de aquellos. ${ }^{63}$ La fundación se realizó irregularmente -según sentenció la corte madrileña más adelante-, lo cual dio lugar a este proceso que concluyó de modo provisorio en 1805. Un dato significativo es que Ambrosio era bisnieto de Cristóbal Funes, donante de las tierras sobre las cuales se había asentado el pueblo de indios. Ambrosio intervino como comisionado del virrey para que realizara la revisión íntegra del procedimiento. Además, como vimos, Funes había sido alcalde de primer voto en 1797 cuando el cabildo se había opuesto a la fundación propiciada por la intendencia. En definitiva, Ambrosio sostuvo que tal fundación cercenaba la integridad de los derechos jurisdiccionales del cabildo de Córdoba, pues la creación de una villa implicaba constituir un nuevo espacio jurisdiccional, independiente del ayuntamiento de la capital provincial; no era una fundación sobre territorio vacuo, sino un espacio jurisdiccional perteneciente a Córdoba y

60 CMPC docs. números 6034 (Solicitan respecto a la Universidad y al Colegio de Monserrat tome las medidas que estiman le dictaría la prudencia como necesarias, 16 de junio de 1799), 6035 (Alude al estado de la Universidad y el Colegio de Monserrat, al Rector P. Súlivan y al apoyo que a éste prestaban algunos cabildantes, 1802) y 6051 (Representación a propósito del Colegio de Monserrat y en especial de su Rector el P. Súlivan, 16 de octubre 1801). Una de las familias más conformadas con las políticas reformistas de Sobremonte, la de José Rodríguez y sus hijos Victorino y Justo, estuvo vinculada a la administración de los bienes que dejaron los jesuitas tras su expulsión. LUQUE COLOMBRES, Carlos "El Doctor Victorino Rodríguez...", cit., pp. 344-421.

61 CMPC doc. números 6051, cit. y 6040 (Instrucción y prevenciones que da a su apoderado el Teniente Coronel Félix Mestre para que agite ante el Exmo Sr. Virrey la reparación de la decadencia de la Universidad y Colegio de Monserrat, que promueve como vezino y Alcalde de primer voto interino de esta ciudad, procurando así mismo la vindicación sobre las quejas que tiene interpuestas del Fr. Pedro Súlivan, 18 de mayo de 1799).

62 Resume Groussac así estas pretensiones de Gregorio Funes: "Conseguido el deanato, constituyóse en pretendiente perpetuo á todos los obispados de vacantes de América y hasta de Filipinas"; en GROUSSAC, Paul Santiago de Liniers..., cit., p. 361. Lo que Groussac atribuye indirectamente a la incapacidad de Gregorio Funes, correspondería más bien a la política metropolitana de negar sillas episcopales a los criollos.

63 AGN, IX, 23-4-5. Agradecemos a Sonia Tell que nos haya facilitado la transcripción de este documento. 
en cuyo desmedro se creaba. ${ }^{64}$ En conjunto, sus intervenciones en el expediente defienden una tradicional situación de equilibrio y convivencia lograda por quienes habían hecho la conquista -sus propios antecesores-. En tal equilibrio, aparecen las familias patricias de conquistadores y encomenderos y el cabildo como sus garantes; como contrapartida, Sobremonte y sus funcionarios son pintados como corruptores de un antiguo y respetable orden vigente.

En 1805, Ambrosio fue elegido nuevamente síndico procurador de la ciudad, que era un cargo mucho más a propósito para instigar y litigar que cualquier otro, porque por él podía invocar el interés general. Gregorio y Ambrosio obtuvieron de Liniers en 1807 el traspaso de las instituciones educativas, recayendo sobre aquel el rectorado de ambos establecimientos. La estrategia que permitió esto fue la de una insistente lucha judicial, pues entre 1798 y 1807 excitaron el sistema judicial canónico y político del virreinato con cuanto recurso administrativo existiera. ${ }^{65}$

Puede decirse, al estudiar su desempeño administrativo y judicial hasta los primeros años del siglo XIX, que Ambrosio Funes bregó porque la Universidad, el Monserrat y el obispado estuvieran en manos de criollos; se quejaba de que en el otorgamiento de los cargos se prefería a los europeos sobre los americanos (bien lo sabía por su propio hermano, que no pudo llegar a obispo); y, en especial, defendía la integridad de los privilegios de los cabildos frente a los agentes de la monarquía (gobernadores, delegados de la real hacienda, oidores, etc.), cuyas jurisdicciones habían sido creadas o rediseñadas por la Real Ordenanza de Intendentes y demás reformas jurídico-políticas en el virreinato. ${ }^{66}$ Estos tópicos constituyen el núcleo de su agenda institucional de restauración y rehabilitación en tiempos de un creciente rol de los europeos en el gobierno de las Indias. ${ }^{67}$

64 Estas fundaciones eran políticas de los funcionarios borbónicos, particularmente de Sobremonte; RUSTÁN, María Ester De perjudiciales a pobladores de frontera. Poblamiento de la frontera sur de la Gobernación Intendencia de Córdoba a fines del siglo XVIII, Ferreyra Ediciones, Córdoba, 2005

65 AGN, IX, 9-2-10 (Gobierno de Córdoba. Correspondencia del Virrey, 1806-1807 [Descargo de Rodríguez ante la audiencia, por las acusaciones hechas por Funes en su contra]). También en las actas del cabildo de Córdoba de 1807, publicadas en CABILDO DE CÓRDOBA, Actas capitulares..., cit.

66 Rees Jones hace un prolijo repaso de las reformas de intendencia y hacienda que en el último tercio del siglo XVIII impusola corona a las instituciones locales del nuevo virreinato; REES JONES, Ricardo El Superintendente Manuel Ignacio Fernández (1778-1783). Las reformas borbónicas en el Virreinato de Buenos Aires, Instituto de Investigaciones de Historia del Derecho, Buenos Aires, 1992.

$67 \quad$ PUNTA, Ana Inés Córdoba borbónica..., cit., p. 111. 


\section{La jurisdicción de Córdoba entre 1797 y 1809}

La crítica de Ambrosio era persistente contra las reformas de Carlos III y Carlos IV y sus ejecutores en Córdoba del Tucumán; expresaba en su accionar la tensión que aquel complejo sistema reformista había suscitado entre los americanos. Agregamos también su escasa participación en los beneficios de una mayor recaudación generalizada que se dio a fines del siglo XVIII. Pero hubo más políticas borbónicas que agraviaban el viejo orden jurídico-social colonial, en especial en lo que era la toma de decisiones en la jurisdicción cordobesa: el gobierno y la administración. Esa interacción entre borbónicos y opositores, especialmente durante el periodo de construcción de la Intendencia de Córdoba del Tucumán -que corresponde a la actuación del marqués de Sobremonte como su primer titular, por un largo periodo de casi 14 años (17831797)-, es presentada por las fuentes como una jurisdicción cuyas instituciones funcionaban bajo la dirección de una facción borbónica sobremontista; ${ }^{68}$ mientras el marqués residió en Córdoba, Ambrosio Funes rompía la uniformidad de opiniones con alguna queja o alboroto que, a su vez, ponía en marcha una serie de mecanismos de ajuste. ${ }^{69}$ La agitación se acentuó llegando al siglo $\mathrm{XIX}^{70}$, al retirarse Sobremonte hacia sus nuevas funciones (sub-inspector general de Ejército de todo el virreinato, entre 1797 y 1804); en el cénit de la hegemonía del marqués, las voces anti-borbónicas se hicieron más numerosas y fuertes. ${ }^{71}$ Ambrosio Funes, Antonio Arredondo, Benito Rueda, Antonio Savid, Francisco Antonio González, Francisco de Recalde y varios más, ni bien el marqués se fue de Córdoba, fueron contradiciendo la uniformidad pretendida y casi lograda por aquel y sus aliados: Victorino Rodríguez, Nicolás Pérez del Viso, Santiago de Allende, etc. ${ }^{72}$ A partir de entonces, las fuentes sugieren una lucha entre dos facciones muy bien organizadas que tuvo momentos de gran virulencia, alternándose en el predominio del cabildo con proyectos opuestos. Estos hechos muestran una mayor vitalidad en los juegos de poder de la elite cordobesa y acompañan bien la existencia paralela de un sentimiento de simpatía de algunos cordobeses hacia proyectos de reivindicación y reformulación del lugar del virreinato y sus provincias dentro de la

\footnotetext{
68 DAINOTTO, Edgardo Política y poder..., cit., en especial los capítulos V y VII.

69 CMPC doc. núm. 5975, cit.

70 Virginia Ramos ha ilustrado este punto con un muy buen relato de las vicisitudes de dos facciones enfrentadas en Córdoba; RAMOS, Virginia "El enemigo en casa: repercusiones, debates y conflictos facciosos ante la presencia de prisioneros ingleses en Córdoba del Tucumán (1806-1807)", en Anuario de la Escuela de Historia. Virtual, núm. 11, Universidad Nacional de Córdoba, Córdoba, 2017; pp. 1-22.

71 CABILDO DE CÓRDOBA, Actas capitulares..., cit.

72 LUQUE COLOMBRES, Carlos “El Doctor Victorino Rodríguez...", cit., p. 403, al pie.
} 
monarquía, ${ }^{73}$ porque se hacen visibles las preferencias políticas más allá delos enfrentamientos por cuestiones domésticas.

Entonces, desde 1797 hasta 1810, la historiografía local caracterizó el escenario político de los últimos años coloniales en Córdoba como un campo en que contendieron dos facciones de la elite: la de los sobremontistas y la de los funesistas. ${ }^{74}$ El criterio delimitador era el apoyo o el rechazo a las políticas de Sobremonte como gobernador o virrey, sucesivamente. Los sobremontistas son retratados como amigos leales del ex gobernador intendente y ex virrey, realistas consecuentes cuando la revolución se hizo explícita en Córdoba; a esta facción la sostenían personajes ligados a la burocracia regia recreada en tiempos de su gobernación. En la otra, a los funesistas, portadoras de una larga queja contra la discriminación hacia los americanos y el recrudecimiento de las medidas centralizadoras, revolucionarios en germen, precursores inconscientes de un rompimiento definitivo con la Metrópoli. Así, fijada la fecha de 1810 como un momento en el que este grupo era antiguamente revolucionario y aquel persistentemente realista, las acciones previas de los Funes son leídas como precursoras y las de Rodríguez y Concha (gobernadores de Córdoba y contrarrevolucionarios en 1810) y todos quienes acompañaron las decisiones institucionales, como reaccionarias. ${ }^{75}$ En definitiva, asocian revolución con funesismo, y contrarrevolución con sobremontismo.

Otras interpretaciones -las menos- relativizan la existencia de esta facción cordobesa revolucionaria e independentista; ponen a Ambrosio como mente y brazo de una camarilla de sacristía, amante de las querellas de aldea ${ }^{76}$ contra Sobremonte y sus amigos, y al deán como advenedizo y delator. ${ }^{77}$ Algunos describen el liderazgo de Ambrosio como apenas capitular, exasperantemente local, y ponen a Victorino Rodríguez -múltiple funcionario

\footnotetext{
73 CMPC doc. núm. 5876 (Sobre elecciones del 4 de diciembre de 1800, 20 de febrero de 1802).

74 LUQUE COLOMBRES, Carlos "El doctor Victorino Rodríguez...", cit; pp. 403. BISCHOFF, Efraín Historia de la Provincia de Córdoba, Buenos Aires, 1968.

75 PEÑA, Roberto El pensamiento político del Deán Funes, Universidad Nacional de Córdoba, Córdoba, 1953. Este autor habla de conservadores y renovadores, poniendo a la cabeza de estos a Funes; si bien estas denominaciones se acercan al objeto de estudio en función de los fines políticos de cada facción, no queda claro que las posiciones de los Funes, por ejemplo, fueran renovadoras. La propuesta de Peña queda absorbida por la identificación entre la facción de los Funes con la revolución y la de Sobremonte con la contrarrevolución, que ya tratamos más arriba.

76 DE VEDIA Y MITRE, Mariano El Deán Funes en la historia argentina, Editorial Kraft, Buenos Aires, 1954 [1910].

77 GROUSSAC, Paul Santiago de Liniers, cit. pp. 360 y ss.
} 
borbónico de la Intendencia- como su opositor en temas concejiles, ${ }^{78}$ en el mismo plano de las minucias de oficina. ${ }^{79}$

Estas generalizaciones historiográficas fueron realizadas a partir de la documentación producida principalmente por Ambrosio Funes ${ }^{80}$ y de las numerosas quejas que Rodríguez, Concha, Allende y otros presentaban ante sus superiores por las molestias que Funes producía. ${ }^{81} \mathrm{La}$ designación de sobremontistas es obra de su pluma $^{82}$ y con ella nombraba a todos los funcionarios del gobierno metropolitano que se mostraban bajo la jefatura del marqués: gobernadores, oidores y fiscales de la audiencia; oficiales y demás agentes de la real hacienda; la alta oficialidad de las tropas veteranas, de marina y de milicias, etc. Se identificaban como monárquicos, defensores de los intereses metropolitanos -de los que tomaban su parte bajo la forma de salario o tarifas ${ }^{83}$ - eran específicamente borbónicos, con la carga de centralización y autoritarismo que evocaba ese adjetivo en sus escritos. Eran los mandones, ya dijimos. ${ }^{84}$ Se mostraban también como borbónicos algunos americanos; su participación en el proceso de mayor exacción monetaria y en el funcionariado según les permitió -al menos en Córdoba- la reforma de fines del siglo XVIII, ${ }^{85}$ fue un factor que propició que una parte del vecindario fuese borbónico. ${ }^{86}$ Muchos de estos vecinos criollos fueron fieles a la Metrópoli hasta morir. ${ }^{87}$

$78 \quad$ GROUSSAC, Paul Santiago de Liniers, cit. p. 308.

79 Su insignificancia para el observador actual debe ser corregida por las sugerencias interpretativas de Garavaglia, para quien aquellos eran verdaderos "episodios de una competencia simbólica por el poder". En aquel horizonte cultural se trataban más bien de luchas por apropiación de los símbolos y, a través de ellos, de las realidades políticas que querían expresar: las jerarquías y los vínculos de poder; FRADKIN, Raúl y GARAVAGLIA, Juan Carlos La Argentina colonial. El Río de la Plata entre los siglos XVI y XIX, Siglo XXI, Buenos Aires, 2016, p. 155.

so CMPC doc. núm. 5878, cit. En algunos de sus contemporáneos existía la sospecha de que el mismo Ambrosio lanzaba rumores de hechos inexistentes, contra los que salía luego a combatir; AGN, IX, 9-2-10, cit.

$81 \quad$ AGN, IX, 09-02-10, cit.

82 CMPC doc. núm. 6221, cit.

83 MOUTOUKÍAS, Zacarías y AMARAL, Samuel "Las tramas...", cit; también PUNTA, Ana Inés Córdoba borbónica..., cit., p. 149.

84 MOUTOUKÍAS, Zacarías y AMARAL, Samuel "Las tramas...", cit. En cuanto a las actividades económicas de cada facción, ver: CONVERSO, Félix "El comercio de Córdoba y las invasiones inglesas", en Actas del Cuarto Congreso Nacional y Regional de Historia Argentina, I, celebrado en Cuyo (noviembre de 1977), Buenos Aires, 1979, pp. 355-363; CONVERSO, Félix Los negocios y la política: las redes mercantiles y el poder, Junta provincial de Historia de Córdoba, Córdoba, 1997.

85 DAINOTTO, Edgardo Política y poder..., cit., pp. 131 y ss.

86 Funes enumeró a los funcionarios adeptos al régimen borbónico y metropolitano: CMPC doc. núm. 6221, cit. Manuel Belgrano, con un mayor grado de despersonalización que Funes y con una mirada más amplia, llama a este grupo metropolitanos. BELGRANO, Manuel 
En cambio, el nombre de funesista dado a la facción opuesta a los sobremontistas no aparece como de la época, sino como una construcción historiográfica $^{88}$ que intenta dar unidad al accionar de varios vecinos cordobeses que en diversas instancias habían opinado y actuado en contra de alguna medida borbónica, casi siempre capitaneados por Ambrosio Funes. Tiene utilidad para, mediando la personalización en uno de sus miembros más activos, ilustrar un eje importante de discusión durante el periodo que estudiamos (en particular 1805-1810) en el ámbito cordobés; pero no permite ahondar en otras dimensiones de su representatividad social e inserción regional. Entonces, en tanto que en Córdoba los sobremontistas miraban con desconfianza la presencia pública de vecinos descontentos, a los que denostaban y excluían de la esfera administrativa, en especial del cabildo, a la facción que se sentía agraviaba por este enfoque y que buscaba revertir sus resultados era el partido que llamamos de los municipalistas, en remplazo de funesistas. Decimos que eran municipalistas, en el sentido de que defendían las antiguas preeminencias y privilegios del cabildo que, como vimos, por aquellos años era una institución revalorizada por las circunstancias que pusieron en vilo a Europa y a América. ${ }^{89}$ Ambrosio, con sus intervenciones, dotó al municipalismo de Córdoba de cierto tipo de memoria sobre el pasado en busca de deslegitimar la acción reformista de las tres décadas anteriores, para recuperar el protagonismo y la participación de las familias patricias. ${ }^{90}$ Él ejercía influencia y aportaba dirección política sobre una facción de la elite cordobesa ${ }^{91}$ que buscaba devolver a los cabildos manejados por los vecinos de cada jurisdicción el rol de mediadores entre la corona y los pueblos; esa edad de oro, decían, había sido una época en que el monopolio comercial -antes de las

\footnotetext{
"Autobiografía", en WEINBERG, Gregorio (comp.) Escritos económicos, Editorial Raigal, Buenos Aires, 1954, pp. 47-62.

87 Es el caso de Victorino Rodríguez y Santiago Alejo de Allende, fusilados en la contrarrevolución de agosto de 1810.

88 LUQUE COLOMBRES, Carlos “El Doctor Victorino Rodríguez...", cit., p. 403.

89 Es lo que Chiaramonte llama "el cimiento 'municipal' de los futuros estados"; CHIARAMONTE, José Carlos Ciudades, provincias, Estados..., cit., p. 95.

90 Abundaban los escritos que exhumaban "las antiguas libertades" que habrían representado, en tiempos de los Trastámara, las prácticas de representación de las ciudades de Castilla; HALPERIN DONGHI, Tulio Tradición política española e ideología revolucionaria de Mayo, Prometeo, Buenos Aires, 2009, pp. 138 y ss.

91 “...algunos de los Individuos de ese Ilustre cuerpo, y en especial los Señores Alcaldes, y con más particularidad el de primer voto [Ambrosio Funes] a quien ciegamente siguen otros", en AHPC, Gobierno, Tomo 30, legajo 9 (Respuesta del Dr. Victorino Rodríguez al Cabildo de Córdoba a raíz de una acusación éste, 2 de abril de 1807); reproducido en LUQUE COLOMBRES, Carlos “El doctor Victorino Rodríguez...", cit., pp. 444-445.
} 
reformas de fines del XVIII ${ }^{92}$ - garantizaba un sistema de distribución que manejaban en buena parte redes de vecinos y de agentes de la Metrópoli. ${ }^{93}$

Es importante tener presente que no encontramos factores de nacimiento o étnicos -europeos y americanos, por ejemplo-, que sean definitorios de las identidades políticas de los individuos; Funes escribe sobre el "partido opuesto", o sobre los "buenos vecinos" y el "lado nuestro", refiriéndose a su facción, sin calificaciones de índole étnica o por su procedencia. La diferenciación era política, exclusivamente; en ambos grupos había criollos, europeos, funcionarios, hacendados... De allí que no recurramos a designaciones como "sector europeo o español", "partido criollista", etc. ${ }^{94}$ Nos movemos con el concepto de identidad política municipalista, para acotar el fenómeno que estudiamos a su manifestación en ámbito de la lucha por el poder local y regional.

La dinámica que ambas facciones imprimieron a la vida institucional de Córdoba durante el periodo estudiado trascendió los enfrentamientos internos de aldeas pues se anudaron en redes que abarcaban espacios muy amplios, construyendo, como dijimos, identidades políticas bien definidas. Las coincidencias ideológicas tomaron cuerpo para transformarse en escuetos programas de intervención compartidos por individuos y grupos de distintos lugares. La principal convicción común era la importancia de los cabildos en el encuadre del desastre político y social que la política internacional de Carlos IV y Godoy provocaba. Y por ello ambas facciones luchaban por hegemonizar sus mecanismos. ${ }^{95}$ La diferencia fue que mientras los borbónicos sobremontistas lo hacían para anular su impronta autonómica, los municipalistas querían radicalizarla, transformando a los ayuntamientos en los órganos locales que administrarían unas provincias sin rey. ${ }^{96}$

\section{Distinguir para no traicionar: monarquía y gobierno}

92 Para ver con detalle la evolución fáctica del tema comercial, ver SEGRETI, Carlos S.A. "El partido español. La facción alzaguista", en Anuario del Departamento de Historia, Universidad Nacional de Córdoba. Año 1, núm. 1, Córdoba, 1963, pp. 331-388 [en especial p. 358].

93 BRADING, David "La España de los Borbones y su imperio americano", en América Latina en la época colonial. 1. España y América de 1492 a 1808, Crítica, Barcelona, 2002 [1990], pp. 269-310. Schlez plantea la importancia de la participación en el monopolio en la consolidación de las posiciones de privilegio en la sociedad tardo-colonial; SCHLEZ, Mariano Dios, rey y monopolio..., cit., pp. 42, 44 y 63.

$94 \quad$ CMPC docs. números 6030, 5876, 6227, cits.

95 HALPERIN DONGHI, Tulio Guerra y finanzas en los orígenes del Estado argentino (17911850), Prometeo, Buenos Aires, 2005, p. 73; también: PORTILLO VALDÉS, José María Crisis atlántica. Autonomía e independencia en la crisis de la monarquía hispana, Marcial Pons, Madrid, 2006, p. 53.

96 CHIARAMONTE, José Carlos Ciudades, provincias, Estados..., cit., pp. 95 y ss. 
En 1804 se inicia un periodo problemático en el virreinato para las relaciones entre los cabildos y los agentes de la Metrópoli, en parte por culpa del marqués de Sobremonte, nuevo virrey. Como ya dijimos, fue gobernador-intendente de Córdoba del Tucumán (1783-1797); obtuvo la sub-inspectoría general de ejército (1797-1804) y el virreinato (1804-1806/7). Encargado provisionalmente de la tarea por muerte del virrey titular, tuvo un inicio auspicioso; en mayo de 1804 el cabildo de Buenos Aires pidió al rey que lo confirmara como titular. En general todas las instituciones festejaron su ascenso. Pero esto duró poco; inmediatamente comenzaron las disputas con el ayuntamiento de la capital, al que el virrey veía como órgano de plebeyos ricos pero despojados de nobleza y de amor a la Metrópoli. Los problemas que tenía el marqués con aquel cabildo fueron del mismo tenor de los que había tenido en Córdoba: resultaban de su esfuerzo por imponer simbólica y prácticamente la soberanía del rey que él representaba sobre la Iglesia y, en especial, sobre el municipio, cuyo cabildo era casi íntegramente un órgano de comerciantes y hacendados europeos afincados en la capital virreinal. ${ }^{97}$ Pero la diferencia era el peso político y económico del cabildo porteño respecto del mediterráneo. Sumó el marqués en su contra el especial descontento de la facción monopolista a la que pertenecía Álzaga:98 para los monopolistas, Sobremonte representaba a los autores de los permisos de importación que la corte otorgaba por fuera del método de exclusividad cada vez más numerosos-, del enrarecimiento de los envíos desde Cádiz por las guerras y del contrabando que no combatían adecuadamente. ${ }^{99}$ Todo esto ocurrió en 1805, año en que se dieron hechos de recíproco desdén; la autoridad regia que investía Sobremonte como virrey, crecía en desprestigio a causa del destrato hacia los súbditos rioplatenses, en especial los vinculados al debilitado monopolio. ${ }^{100}$

Ambrosio, desde Córdoba, en este contexto de mutua desconfianza entre instituciones regias y municipales en varias jurisdicciones, se acercó a sectores e individuos afines ideológicamente de la capital y de Montevideo; ${ }^{101}$ con ellos,

97 AGN, IX, 26-7-10, cit. También: Mayo documental, VII, doc. núm. 870, p. 204, cit.

98 SEGRETI, Carlos S.A. "La facción española...", cit. p. 380; MOUTOUKÍAS, Zacarías y AMARAL, Samuel “Las tramas de la acción política...", cit., p. 110.

99 SEGRETI, Carlos S.A. "La facción española...", cit. pp. 380 y 386; HALPERIN DONGHI, Tulio Guerra y finanzas..., cit., p. 86.

100 CORBELLINI, Enrique La revolución de Mayo y sus antecedentes desde las Invasiones Inglesas, I, Lajouane Editores, Buenos Aires, 1950, pp. 85 y ss. Para una comparación con los gestos que se le conocieron en Córdoba, ver DAINOTTO, Edgardo Poder y política..., cit., capítulos I, V y VII.C

101 Es la opinión de Mariano Torrente, historiador español, que decía, en el contexto de los problemas entre de Elío y Liniers, y de la asonada del 1 de enero de 1809: “Desde el principio de estas conmociones se había observado en los ayuntamientos de Montevideo i Buenos Aires una estrecha correspondencia que arrojaba las mayores alarmas, i hacia sospechar que aquel fatal empeño se comunicaría prontamente por todas las clases". TORRENTE, Mariano Historia de la 
formó una red de personalidades socialmente relevantes que cuestionaban la legitimidad del gobierno vigente sin agraviar al orden monárquico, cuando pasaban muchos meses durante el segundo lustro del siglo XIX en que no se recibían noticias de la Metrópoli. ${ }^{102}$ No hablamos de una conspiración, sino de una coincidencia temporal de convicciones y acciones que les permitió en sus respectivos lugares de actuación cuestionar a los agentes de la corona, ensamblados por sus recíprocos respaldos y la circulación de datos. En el imaginario trasuntado por la correspondencia entre Funes y Álzaga, como anticipamos, y en los documentos de la Junta Gubernativa de Montevideo, Manuel Godoy, el ministro favorito de Carlos IV, era la causa inmediata y real de los males de América. Su inmoralidad y falta de patriotismo, según ellos, se mostraba en dos problemáticas afines: una, la designación de gobernantes coloniales ineptos, propensos a la corrupción y venalidad-deméritos que achacaban al mismo Godoy-; otra, la de ser un afrancesado, un agente al servicio de Napoleón. Con estos factores a la vista, Ambrosio aprovechó la diferencia entre monarquía y gobierno, para fortalecer su posición y dotarla de legitimidad. No hay ninguna originalidad en esta distinción; pero su uso tuvo efectos prácticos notables en las acciones de esta red.Gobierno designaba a la conducta de los agentes de la monarquía y a las medidas administrativas que tomaban; por lo tanto, quedaban dentro de lo discutible. Se podía criticar a un agente de la monarquía sin atacar al monarca; los derechos de este estaban fuera de discusión. ${ }^{103}$ Fue un recurso ideológico muy potente que compartió con Martín de Álzaga y con Francisco de Elio, que se mostró operativo cuando se produjo la invasión francesa a la península (desde mayo de 1808). Vivar al rey pero conspirar contra sus delegados y emisarios -los mandones- es un recurso legitimador que tendrá gran alcance en la definición de todo los proyectos en danza entre 1805 y 1810; es la pasta de la que están hechas frases como "Viva el rey, mueran sus delegados"104 y "Muera el mal govierno, muera el govierno francés, viva Fernando $7^{\circ \prime} .{ }^{105}$ Servía tanto a americanos como a europeos:

Revolución Hispano-Americana, Imprenta de Moreno, Madrid, 1830. p. 22. En igual sentido, con otra documentación de respaldo, CANTER, Juan "Las sociedades secretas y literarias", en LEVENE, Ricardo (dir.) Historia de la Nación Argentina.Desde los orígenes hasta la organización definitiva en 1862, Editorial Ateneo, Buenos Aires, 1941, pp. 189-305; y WILLIAMS ÁLZAGA, Enrique Dos revoluciones..., cit.

102 HALPERIN DONGHI, Tulio Guerra y finanzas..., cit., p.72.

103 PEIRE, Jaime “De la dominación 'suave y dulce' a la soberanía del pueblo, 1767-1825", en PEIRE, Jaime, DI PASQUALE, Mariano y AMADORI, Arrigo Ideología, prácticas y discursos. La construcción cultural del mundo social, siglo XVII-XIX, Edutref, Sáenz Peña, 2013; pp. 23-76.

$104 \quad$ CMPC doc. núm. 6161 (Algunos detalles sobre los sucesos que precedieron a la Revolución de Mayo, 1810)

105 Mayo documental, IX, doc. núm. 1160, p. 308 (Copia de autos labrados sobre la causa formada con motivo de los sucesos de Buenos Aires, del $1^{\circ}$ de enero de 1809...). También en 
Álzaga instaba a Funes a que informara a los altos tribunales peninsulares contra los monárquicos sobremontistas de Córdoba: “y de este modo llegará el monarca á conocer que generalmente no tiene por estas partes sino a malos servidores y traidores". ${ }^{106}$ Su ventaja era que permitía el ejercicio de la crítica sin abandonar el campo de legitimidad vigente, que era el de la monarquía católica. ${ }^{107}$

\section{Las invasiones inglesas: la causa del cabildo se fortalece}

A pesar de su brevedad, la ocupación inglesa de 1806 incidió en jurisdicciones como Córdoba con significativos efectos políticos. ${ }^{108}$ Permitió a la facción municipalista cordobesa, ya no solo a Funes, integrarse más fuertemente con los intereses del cabildo de la capital; no está de más resaltar que el cabildo de Buenos Aires se veía en el centro de las luchas por la reivindicación de su rol dentro del esquema colonial, y las invasiones impulsaron este reclamo. El ayuntamiento del puerto recurrió a los cabildos del interior para hacer frente a la militarización de la plaza porteña. ${ }^{109}$ Esto constituyó también, al menos para la de Córdoba, la oportunidad de demostrar que la facción de la elite que se sentía vejada por las reformas borbónicas, relegada del poder y disminuida en sus fuerzas por la mayor intervención metropolitana, era capaz de sostener en pie a las colonias contra los ataques de los bretones, ${ }^{110}$ sin ayuda de la Metrópoli. El archivo de Funes conceptualiza así a las invasiones: "La perdida de dicha capital acaecida en 27 de junio de 1806, quiza mas fue un beneficio de Dios que un castigo". ${ }^{111}$ La facción borbónica se dedicó a minimizar ese triunfo, como modo de defender la actuación del virrey Sobremonte, cuya conducta había

Chuquisaca, en mayo de 1809, la revuelta usó esa fórmula; LUCENA GIRALDO, Manuel Naciones de rebeldes..., cit. p. 86.

106 CMPC doc. núm. 5712 ([Martin de Álzaga] Avisa recibo documentación con destino al tribunal. Algo en cuanto al coronel Allende. Juicio respecto al Gob. De la Concha. Sobre acciones por la posesión de Colonia, fines de 1807)

107 En los hechos, esa distinción alcanzó una claridad que no tenían los diccionarios. Por ejemplo, en la edición de 1817, la más cercana temporalmente a los hechos, el Diccionario de la Academia Española dice en la entrada monarquía "Forma de gobierno en que manda uno solo con arreglo á leyes fijas y estables".

108 Para Converso, las invasiones no alteraron los envíos recíprocos entre Córdoba y el puerto; CONVERSO, Félix "El comercio de Córdoba y las invasiones inglesas...", cit., pp. 361 y ss. De manera más general, Halperin plantea que justamente los productos locales encontraron salida en la población militarizada del puerto durante las interrupciones atlánticas o bloqueos; HALPERIN DONGHI, Tulio Guerra y finanzas..., cit., pp. 72 y ss.

109 CMPC doc. núm. 5692, cit. También en WILLIAMS ÁLZAGA, Enrique Dos revoluciones..., cit., p. 126.

$110 \quad$ AHPC Gobierno, Tomo 29, legajo 25, fs. 350.

111 CMPC doc. núm. 6161, cit. 
quedado en entredicho. ${ }^{112}$ Frente a ello, Funes bregaba por un reconocimiento institucional más claro de esos triunfos; ${ }^{113}$ su lucha por hacer que el cabildo de Córdoba sufragase parte de los gastos de aquella militarización -aunque de poco fruto- fue incansable. ${ }^{114}$ La oposición de los monárquicos no hizo más que realzar la tarea de Funes a los ojos capitalinos. Igual ocurría en su intento de que el cabildo celebrara con mayor pompa que la intendencia sobremontista las victorias porteñas y en hacer notar al cabildo de Buenos Aires que tanto el intendente interino de Córdoba Victorino Rodríguez (1805-1807) ${ }^{115}$ como su comandante de armas Santiago Alejo de Allende se habían mostrado indiferentes a los triunfos celebrados (agosto de 1806); Funes acusaba al ministro Godoy de no haberse interesado en proteger a las provincias de ultramar, y a Sobremonte y a sus seguidores de imitarlo en complicidad. ${ }^{116}$

El impacto que tuvo la invasión y la reconquista de Buenos Aires en la elección de cabildantes cordobeses para 1807 fue claro: permitió el triunfo del bando de Ambrosio, quien fue elegido alcalde de primer voto por muy amplia mayoría; contra ello, parece que Rodríguez no pudo hacer nada, porque Ambrosio en aquel momento formaba parte del grupo que había logrado la reconquista: el de Álzaga y Liniers. ${ }^{117}$ A esto, recordemos, Funes lo había logrado con su prédica contra la huida de Sobremonte, con la exaltación de la valentía porteña, con sus campañas de recaudación para sostener las milicias de la capital, con la saturación de escritos enviados a la corte dando cuenta de la situación local y regional, etc. Hay que tener presente que entre quienes votaron esa lista encabezada por Funes hubo regidores que habitualmente votaban conformes con el gobernador-intendente interino Rodríguez, pero que frente al desprestigio que trajo la huida de Sobremonte y demás eventos de ese año, se sentían autorizados a optar por quien había acertado en sus críticas. Esta

112 Archivo Histórico Nacional, España (en adelante AHN), ESTADO, 55, E.44 (Buenos Aires. Comunicaciones sobre la lealtad del virreinato del Río de la Plata. Cabildo de Buenos Aires). El cabildo de Buenos Aires acusa a Godoy de haber despreciado esos triunfos.

113 CMPC doc. núm. 5917 ([Ambrosio Funes] Le comunica [a Liniers] pormenores relacionados con la llegada a Córdoba de noticias sobre la reconquista, julio de 1807).

114 CONVERSO, Félix "El comercio de Córdoba...", cit., p. 362 y ss.

115 LUQUE COLOMBRES, Carlos “El Doctor Victorino Rodríguez...”, cit., pp. 399-402.

116 AHPC, Gobierno, Tomo 29, legajo 25, cit; CMPC doc. núm. 6249, cit.

117 Una de las piezas historiográficas cordobesas más antiguas, la Crónica..., de Ignacio Garzón, da cuenta, a fines del siglo XIX, de la necesidad de no interpretar los efectos de las Invasiones desde los acontecimientos revolucionarios de 1810: "Las demostraciones de la autoridad de la capital, muy significativas y claras contra el sobremontismo, trastocó algunos votos en el Ayuntamiento de Córdoba, que más tarde, siguiendo las inspiraciones del alcalde don Ambrosio Funes, habían de servir a la causa de la Independencia, sin preverlo indudablemente y solo por espíritu de oposición á todo gobierno que no sancionaría su preponderancia local. Pasaba esto tres años antes de la Revolución"; GARZÓN, Ignacio Crónica de Córdoba, Tomo I, Alfonso Aveta Editor, Córdoba, 1898, p. 101. 
disponibilidad de varios regidores a acompañar con sus votos a una facción o a otra, parece estar en la dinámica misma del sistema capitular durante este periodo (1805-1810); este funcionaría con dos grupos opuestos, relativamente pequeños y compactos, motores de las estrategias, y un grupo numéricamente mayor, propenso a votar con cierta libertad. ${ }^{118}$ En 1807 hubo regidores que le dieron el voto a Funes y que antes habían votado con los monárquicos; y después se dio a la inversa. ${ }^{119}$ Funes, fortalecido, se constituyó en un hostigador continuo de Rodríguez, cuyo patrón -Sobremonte- había caído en desgracia. Las actas de cabildo de ese año muestran cómo se le objetaba al intendente la mayoría de sus decisiones y se atacaba a miembros de su entorno -los Allende. ${ }^{120}$ Se le negó al gobernador interino que el cabildo fuera a buscarlo a su casa para luego dirigirse a la catedral en los oficios públicos, lo que constituyó uno de los más audaces desaires del cuerpo municipal. ${ }^{121}$ Los más de cuatro mil pesos que se pudieron remitir al cabildo de la capital se recolectaron durante su alcaldía de 1807; ${ }^{122}$ pero aunque era una suma pequeña permitió calificar a la de Córdoba como una jurisdicción auxiliadora de la plaza de Buenos Aires: "Siendo la Capital dela Provincia de Cordoba la que ha sufragado mas auxilios á la Capital, y á Montevideo en tres expediciones con más de tres mil hombres y con sus donativos de dinero, fornituras, caballos..."123

\footnotetext{
118 Converso hacer notar, al estudiar la composición ideológica de los comerciantes cordobeses, que se dio el mismo fenómeno: dos grupos adheridos o a Funes o a los sobremontistas, y uno numéricamente mayor, de actuación más vinculada a la defensa de intereses concretos; CONVERSO, Félix "El comercio de Córdoba...", cit.

119 El mismo Ambrosio Funes lanza, en la nocturnidad de las cartas privadas, duras críticas contra quienes acompañan con su voto en el Cabildo sus iniciativas. Un ejemplo es lo que escribió en 1806, contra Las Heras ("podrido de años y picardías") y Riobóo ("regidor medio extrafalario"). CMPC docs. números 6223 (Apreciaciones relacionadas con la ocupación de Bs As por los ingleses y operaciones que le precedieron..., 1806) y 5875 (Antonio Las Heras Canseco solicita al Cabildo de Córdoba..., 8 de mayo de 1801).

120 CABILDO DE CÓRDOBA, Actas capitulares, cit. (actas de enero, febrero, marzo y abril); también CMPC, doc. núm. 5712 (Carta de Álzaga a Funes, 1807).

121 CABILDO DE CÓRDOBA, Actas capitulares, cit., acta del 3 de abril de 1807. No solo desde el cabildo se quejaban varios vecinos cercanos a Funes de los funcionarios sobremontistas: algunos que formaban parte de la Hermandad de la Caridad lograron la atención del virrey Liniers al acusar a Rodríguez de haberles suspendido una función religiosa prevista para la misma hora en que el Tesorero de la Real Hacienda, Moreno, hacía una fiesta en su casa. Los hechos parecen haber sido exactamente opuestos -los hermanos de la Caridad habrían adelantado una procesión para boicotear la fiesta del funcionario-; AGN, IX, 09-02-10, cit. Smietniansky hace un excelente estudio antropológico-histórico de los quiebres voluntarios a los protocolos como manifestación de descontento y posicionamiento político; SMIETNIANSKY, Silvina Ritual, tiempo y poder: una aproximación antropológica a las instituciones del gobierno colonial (Gobernación del Tucumán, siglos XVII y XVIII), Prohistoria Ediciones, Rosario, 2013, pp. 89-97.

122 CMPC doc. núm. 5692, cit.

123 CMPC doc. núm. 6252, cit.
} 
En la elección de capitulares de enero de 1807 en la capital, Álzaga -igual que Funes en Córdoba-, accedió a la alcaldía de primer voto de su cabildo. Los paralelos entre Álzaga y Funes son múltiples y significativos: el vasco, desde 1785 hasta 1808, participó 7 veces en tareas concejiles; fue prior del consulado y organizador de las milicias de la reconquista. Pero las similitudes no se agotan en las trayectorias institucionales. Ambos pensaban que tanto en situación de vacancia de la corona (lo que sucedió poco después) como en la de una independencia del tipo "de que goza la Pensilvania", 124 la fórmula política adecuada era la confederación de jurisdicciones independientes gobernadas por sus cabildos, jerárquicamente ordenados mirando hacia el puerto. ${ }^{125} \mathrm{El}$ comerciante de Buenos Aires Francisco de Letamendi, del entorno de Álzaga y representante comercial de Ambrosio en la capital, era explícito en proponerle al cordobés que ambos ayuntamientos operaran coordinadamente para hacer frente a los gobernantes coloniales; el objetivo era "que queden los cabildos con otro nervio que el que han tenido hasta ahora". ${ }^{126}$

Aunque rescatada Buenos Aires en agosto de 1806, en febrero de 1807 cayó Montevideo por el sitio inglés; la elite porteña, forzando viejas instituciones o ignorándolas, destituyó definitivamente al marqués de Sobremonte como virrey. Liniers y la audiencia, que se habían repartido provisionalmente la autoridad virreinal (militar y política, respectivamente), ${ }^{127}$ recurrían al virrey peruano José de Abascal (1806-1816) para pedir ayuda reconociéndolo, en los hechos, como un jefe. Además, todo el Pacífico peruano (Panamá y demás lugares costeros que no eran de su jurisdicción) le reclamaba asistencia a ese virrey. ${ }^{128}$ Por intentar al menos satisfacer esas solicitudes, este

\footnotetext{
124 "Pensilvania" es una forma de referirse a la constitución de los EEUU de 1787, cuando se creó la organización política encabezada por un poder ejecutivo fuerte, separado del legislativo; AGN, IX, 26-7-10 (Invasiones Inglesas. Correspondencia y varios, 1807). WILLIAMS ÁLZAGA, Enrique Dos revoluciones..., cit., p. 123.

$125 \quad$ CMPC doc. núm. 5694 ([El cabildo de Buenos Aires] Expresa agradecimiento por los auxilios prestados con motivo de la invasión inglesa y sus ulterioridades y solicita nuevo donativo..., 27 de febrero de 1810)

126 Carta de Letamendi a Funes, de 27 de febrero de 1808, transcrita en MARTÍNEZ PAZ, Enrique Papeles..., cit., p. 203. Para Martínez Paz, "eran los Cabildos, condensación de las fuerzas populares, los que se aprestaban a disputar a las autoridades españolas la dirección de las colonias"; p. 143. Mariano Moreno estaba en el grupo alzaguista (WILLIAMS ÁLZAGA, Enrique Dos revoluciones..., cit., p. 204). En CMPC doc. núm. 6249 cit., que podría ser un pasquín bajo la apariencia de una carta de un aristócrata a otro, Funes pone en boca del escritor la recomendación de Mariano Moreno para una plaza de oidor de la Audiencia de Buenos Aires, a principios de 1810.

127 SAAVEDRA, Cornelio Memoria Autógrafa..., cit., pp. 31-46.

128 ABASCAL, José Fernando Memoria de Gobierno..., cit., I, p. 460.
} 
virrey limeño se transformaba en el referente monárquico y fidelista del hemisferio sur hispanoamericano. ${ }^{129}$

El esperado segundo desembarco inglés se dio el 28 de junio de 1807; Liniers era el comandante indiscutido y tenía el apoyo de Abascal; el francés actuaba como virrey interino desde mayo. ${ }^{130}$ La defensa de la ciudad fue exitosa. Liniers, al informar a la península de los hechos, reconoció haber tenido en Abascal la ayuda que permitió salir al cruce de la invasión;'131 de igual modo, el archivo del virrey limeño reboza de agradecimientos de las instituciones de Buenos Aires. La dependencia de los agentes de la corona en Buenos Aires hacia Lima había quedado expuesta; por su lado, eso muestra la fortaleza del ayuntamiento capitalino, que en juntas generales o cabildos abiertos provocaba profundos reacomodamiento en el gobierno colonial. ${ }^{132}$ Funes, desde Córdoba, homenajeaba al cabildo de Buenos Aires por su valentía y luchaba contra los representantes de la corona nombrados en tiempos de Godoy. ${ }^{133}$

De este modo el virrey de Lima y su elite incidieron fuertemente en los hechos militares y políticos de Buenos Aires. ${ }^{134}$ También tendieron una mano interesada a la facción monárquica cordobesa. Abascal tejió con ella una pulcra relación de fidelidad, que se basaba en no atacar la memoria de Sobremonte ni en pedir para sí una obediencia que le correspondía a Liniers como virrey y a los gobernadores (Rodríguez y Concha, sucesivamente); en paralelo, Sobremonte seguía ejerciendo cierta influencia sobre las autoridades como la audiencia, la gobernación de Córdoba, algunas comandancias de armas, los franciscanos. ${ }^{135}$ Fruto de esta permanencia no tan velada del virrey depuesto es

129 HAMMET, Brian Revolución y contrarrevolución en México y el Perú. Liberalismo, realeza y separatismo. 1800-1824, Fondo de Cultura Económica, México, 1978; del mismo autor, "La política contrarrevolucionaria del virrey Abascal en el Perú, 1806-1816", en Documento de trabajo núm. 12, Serie Historia núm. 18. Instituto de Estudios Peruanos, Lima, 2000. También VARGAS EZQUERRA, Juan "Cuando no había rey en España, Abascal lo era de América”, en Aportes. Revista de Historia Contemporánea, núm. 55, Universidad de San Pablo, Madrid, 2004, pp. 10-20.

130 LEVENE, Ricardo “La asonada del $1^{\circ}$ de enero de 1809”, en LEVENE, Ricardo (dir.) Historia de la Nación Argentina..., cit., pp. 469-489.

131 También en la relación personal, la ayuda recibida en tiempos de las invasiones es motivo de camaradería y recíprocas obligaciones de honores; ver la carta del 2 de mayo de 1810 de Liniers a Abascal, fechada en Córdoba, en TORRES, Félix Santiago de Liniers. Sus cartas desde la Historia y el Psicoanálisis. 1809-1810. Ferreyra Editor, Córdoba, 2006 (carta núm. 26).

132 Para Abascal, la destitución de Sobremonte, la división del poder institucional y el protagonismo del vecindario a través de "juntas generales" fueron el origen "de las desgracias que afligen hoy [1816] aquel miserable País"; cita de ABASCAL, José Fernando Memoria de Gobierno..., cit., I, 460.

133 CMPC doc. núm. 6252, cit.

$134 \quad$ CMPC doc. núm. 5749 (Informe del Señor Reconquistador de Buenos Aires al Exmo. Sr Príncipe de la Paz, 13 de mayo de 1807).

135 CMPC doc. núm. 6249, cit. 
el memorial que conjuntamente con las autoridades del Potosí y de Córdoba, elevaron al rey en su defensa. ${ }^{136}$

Entre tanto, durante el año de 1807, Liniers, alentado por Abascal, gobernaba el espacio rioplatense bajo la misma lógica con la que habían logrado la reconquista y la defensa de Buenos Aires: con un vecindario militarizado, al amparo de la legitimidad monárquica, con la coordinación de sus colegas marinos $^{137}$-a quienes, como Concha, designó a fines de 1807 para estar al frente de las jurisdicciones del interior-, y haciendo equilibrio entre los funcionarios regios y las elites municipales, principalmente la de la capital.

Las coincidencias temporarias de Funes y Álzaga con Liniers, hasta mediados de $1808,{ }^{138}$ se vieron favorecidas por la forma distante con que el virrey trataba a su antecesor Sobremonte y a sus seguidores; Liniers prefería el sostén que le proporcionaban los municipalistas de la capital y de algunas ciudades del virreinato. ${ }^{139}$ En definitiva, el monarquismo de Liniers aceptaba que su legitimidad provenía de la fuerza de los hechos militares, y daba calce en la toma de decisión a los grupos locales que habían hecho posible la reconquista y la defensa; el monarquismo de Sobremonte, en cambio, era de corte autoritario, exclusivamente metropolitano, indispuesto contra los poderes locales y regionales de su distrito. ${ }^{140}$

Hacia fin de 1807 los monárquicos cordobeses comenzaron a recuperarse; lograron que Liniers ratificara a Dalmacio Allende como regidor propietario, por renuncia que en beneficio de él hiciera su padre, José Antonio. El predominio municipalista se matizaba, al incorporarse Allende, con otra voz favorable a Rodríguez, en lo que fue una política de la gobernación en los años que siguieron: garantizar la mayoría de regidores borbónicos a cualquier precio. Y casi en simultáneo, Liniers desde la capital se mostraba equilibrado y condescendiente con ambas facciones. A la par de los beneficios que dio a los sobremontistas en Córdoba, concedió a los municipalistas su pedido más

\footnotetext{
136 CMPC doc. núm. 6164 ([Pedro Cañete a Sobremonte] A propósito de su exclusión del mando militar de Bs As, de resultas de haber ocupado Bs As los ingleses en 27 de junio de 1806, 26 de noviembre de 1806).

137 MATA, Sara y otro “Un documento interesante. La expulsión del virrey Cisneros. Buenos Aires en junio de 1810", Revista Andes, núm. 15, 2009. También: AYROLO, Valentina “La ciudad cooptada...", cit.

138 CMPC doc. núm. 5712, cit.

139 CMPC doc. núm. 6249, cit.

140 Segreti muestra cómo la facción alzaguista porteña era monopolista y enemiga de Sobremonte, quien con sus medidas había favorecido a quienes buscaban un comercio libre entre Buenos Aires y las colonias extranjeras neutrales. SEGRETI, Carlos S.A. "El partido español...", cit. Para este autor, Sobremonte fue juzgado a partir de la conspiración de este grupo en su contra. Ayrolo también caracteriza al grupo encabezado por Álzaga como monopolista. AYROLO, Valentina "La ciudad cooptada...", cit., p. 12.
} 
insistente y más importante, como vimos arriba: que la universidad y el Monserrat pasaran "al Clero de Córdoba", es decir al hermano de Ambrosio, el deán Gregorio, y el control de sus cuentas al cabildo, no a la gobernación intendencia. ${ }^{141}$

En pocas palabras, las invasiones inglesas consolidaron la empatía y la colaboración de la facción municipalista cordobesa con la respectiva de la capital, encabezada aquella por Ambrosio; los cordobeses condicionaron la actuación de los sobremontistas que resistieron su desprestigio en el cabildo, a la espera de triunfos de Sobremonte que nunca llegaron. Y en la capital, Álzaga y su gente restringía la actuación de Liniers (permanencia indeseada de la época de Godoy) a quien veían como una solución transitoria, como un pasaje necesario hacia un desenlace en el que los cabildos y las elites que los manejaban pudiesen desplegar la totalidad de sus planes. ${ }^{142}$

\section{Los lazos más allá de las jurisdicciones: vencer el aislamiento}

En Córdoba, la persistencia de los monárquicos dio sus frutos en 1808: llegado Concha como gobernador intendente de Córdoba muy a fines de 1807,143 comenzó también su gestión -al igual que Sobremonte, Liniers y luego Cisneros $^{144}$ - con lenguaje y acciones ambiguos. Le respondía Letamendi a Funes: "celebro que el Sr. Concha se haya manifestado adicto a usted". ${ }^{145}$ En efecto, aceptó el nuevo gobernador intendente la nómina de capitulares elegidos el 1 de enero de 1808, que había sido confeccionada por Funes. Accedían recíprocamente a las peticiones de uno y otro, propias de la elección de cabildantes cada 1 de enero. Pero la condescendencia de Concha con Funes y su gente duró pocas semanas. El listado de cabildantes propuesto por el cabildo saliente de 1807, presidido por Funes, era endeble: pasaban las primeras semanas de 1808 y varios capitulares no habían jurado aún. Por ello, Funes extendió su magistratura durante parte del año de 1808, a pesar de que no fue electo para ese ciclo, debido a que su sucesor no se prestó a ello hasta el mes de abril. Sobre la marcha de los primeros meses, el intendente Concha fue mostrándose decididamente anti-municipalista; sus resoluciones, fundadas en dictámenes de Rodríguez -que volvió a su rol de teniente asesor de la

\footnotetext{
141 CMPC doc. núm. 5906 (El Cabildo de Córdoba a Liniers, 18 de diciembre de 1807).

142 AGN, IX, 23-4-1(Proceso por independencia).

143 CMPC doc. núm. 6218, cit.

144 "El Virrey interin no tenga bastantes fuerzas veteranas debe usar de la maior condescendencia, porque son los vecinos los que han de defender aquellas posesiones"; en Mayo documental, IX, doc. núm. 1034, p. 49 (Instrucciones al Virrey de Buenos Ayres..., junio de 1809).

145 MARTINEZ PAZ, Enrique Papeles..., cit., p. 204 (Carta de Letamendi a Ambrosio Funes, 4 de enero de 1808).
} 
intendencia-, no hacían más que realzar la supremacía del derecho regio sobre el municipal: en especial, elegía a los cabildantes para cargos vacantes sin tener en cuenta a los miembros preferidos por los municipalistas y quitó nuevamente al ayuntamiento el control sobre las cuentas del Monserrat que pocos meses antes Liniers le había otorgado. Con estas acciones, ${ }^{146}$ en abril de 1808, Concha ya había logrado doblegar a los municipalistas dentro del cabildo. Inmediatamente Funes pidió licencia para ausentarse de la ciudad, de donde partió el 13 de abril. Se inició lo que sus detractores consideraron un autoexilio en Buenos Aires, luego del consejo de colegas capitulares y comerciantes de la capital, quienes le advertían del riesgo que habría corrido su vida por mano de Concha y Allende; Ambrosio insistía, con poco eco, que solo fue un largo viaje para hacer negocios. ${ }^{147}$ De abril en adelante, sin Funes, los temas de las actas del cabildo volvieron a ser los que tanto apreciaban los borbónicos: farolas, desagües, carreteras, carretillas, carretones, abasto, etc. ${ }^{148}$

Los miembros de la facción municipalista cordobesa creaban redes de alcance regional con grupos cuyos proyectos podían tener algunas coincidencias programáticas. Esto ocurría mientras comenzaba a desarrollarse la guerra con Francia, luego de que Napoleón traicionara la confianza de Carlos IV y de Godoy, pasando a ser enemiga ocupante del territorio peninsular (mayo de 1808). Inglaterra, no obstante haberse transformado en socia de España, agitaba el riesgo de una tercera invasión de la que el ministro portugués Sousa era agorero, pero ahora bajo el pretexto de proteger las colonias de su nueva aliada. ${ }^{149}$ Duró ese cuadro por lo menos hasta noviembre de 1808. Por ello los municipalistas cordobeses, instados por Funes desde Buenos Aires, a pesar de ser minoría dentro del cabildo, insistían en remitir al ayuntamiento del puerto ayuda económica para una eventual tercera defensa. Estos fondos servían para fortalecer la posición del cabildo capitalino en desmedro de Liniers, pues con ellos, con los aportes de los comerciantes y con sus propios,

"el Cabildo [de Buenos Aires] adelantaba el sueldo a los empleados de la administración, incluso los oidores de la Audiencia; asignaba sobresueldos a los militares, con cargo de sus rentas de propios y arbitrios; proveía de uniformes a todos

\footnotetext{
146 CMPC doc. núm. 6218, cit.

147 CMPC doc. núm. 6061, cit.

$148 \quad$ AGN, 6-7-5, legajo 50.

149 CMPC docs. números 5694 y 5694 bis, citados; AHPC, Gobierno. Tomo 30, legajo 30, fs. 533.
} 
los milicianos, gastando medio millón de pesos, e hizo un fuerte préstamo a la Real hacienda". ${ }^{150}$

Concha y Liniers sabotearon en Córdoba estos ingresos para el cabildo de Buenos Aires, ordenando a su ayuntamiento que las colectas fueran depositadas en las cajas reales y que por conducto del intendente Concha se remitiesen al virrey, y no al cabildo de la capital. ${ }^{151}$ En un ataque concertado de las instituciones monárquicas, la audiencia se sumó al virrey y al gobernador, ratificando la preminencia del intendente sobre el cabildo cordobés, pues Concha "está autorizado para entender é imponerse en todos los asuntos que se traten y ventilen en Cavildo como su Presidente". ${ }^{152}$ Mantener aisladas a los ayuntamientos de ambas ciudades y disolver el financiamiento del cabildo de la capital constituyeron acciones de una misma estrategia por debilitar a las facciones municipalistas y a las instituciones. ${ }^{153}$

Arriba dijimos que cuando el cabildo cordobés estaba en manos borbónicas, según sus actas, su agenda era apenas edilicia; desaparecían de su consideración los temas de alta política y se abocaba a la regulación municipal de la vida cotidiana; a lo sumo, el gobernador le permitía al cuerpo responder, por ejemplo, a la corte lusitana, en los mismos términos que lo había hecho el virrey, según un impreso que corría en la época, y por la vía de este que, en definitiva, decidiría si la hacía llegar a los destinatarios. ${ }^{154}$ Esto es el resultado de una convicción ideológica muy arraigada en el esquema borbónico de la política: al cabildo le tocaban los temas de policía, urbanísticos y de higiene; al virrey y gobernadores, las relaciones con otras jurisdicciones, especialmente extranjeras. Nos lo ratifican los hechos de Buenos Aires, donde en julio de 1808, cuando faltaban de noticias de la península y sobraban las amenazas extranjeras, y todas las instituciones recibían oficios de las juntas peninsulares, de Carlota Joaquina, de Goyeneche, de Abascal, etc., el cabildo de Buenos Aires,

\footnotetext{
150 LEVENE, Ricardo "La asonada...", cit. pp. 485 y 486. Para un análisis detenido de la magnitud de las transferencias monetarias por la militarización y su impacto económicopolítico, ver HALPERIN DONGHI, Tulio Guerra y finanzas..., cit., especialmente el Capítulo II.

151 AHPC, Gobierno, Tomo 30, legajo 14, fs. 447 y ss. En 1807 había pasado exactamente lo contrario: el cabildo de Córdoba negó a Saavedra auxilios económicos para su Regimiento de Patricios, argumentando que la colaboración de esa jurisdicción llegaría al cabildo de Buenos Aires; este órgano fue quien distribuyó el donativo. CABILDO DE CÓRDOBA, Actas capitulares..., cit., febrero de 1807, p. 211; algunas proclamas pidiendo donativos están en: AHN, ESTADO,55, E, 44, cit.

152 AHPC, Gobierno, Tomo 30, legajo 30, fs. 531.

153 En la misma dirección iba la sugerencia de Belgrano a Liniers de abrir el comercio a los ingleses, para debilitar a la junta montevideana; BELGRANO, Manuel Autobiografía..., cit.; p. 57. 154 AHPC, Gobierno, Tomo 30, legajo 12, fs. 385.
} 
bastión de los municipalistas de Álzaga, objetó ciertas decisiones de política internacional de Liniers, ${ }^{155}$ quien contestó:

"en los casos pertenecientes al buen orden, policía, abasto, fomento de las artes, y otros asuntos de esta naturaleza, está siempre conforme con las ideas del cuerpo, pero que en las del alto govierno y materias de estado, se reserva obrar conforme a sus conocimientos". ${ }^{156}$

Esta opinión de Liniers era sobre una novedad introducida por los cabildantes de capital: el opinar y querer tomar decisiones sobre cuestiones políticas de alto nivel. ${ }^{157}$

La estadía de Funes en Buenos Aires desde fines de abril de 1808 hasta por lo menos mediados de octubre de 1809 es un síntoma de la gravedad del enfrentamiento entre ambas facciones cordobesas. ${ }^{158}$ Ambrosio fue hospedado por los capitulares más poderosos de Buenos Aires; la descripción de cómo fue recibido por la elite portuaria y los funcionarios regios lo pone a la altura de un personaje de primer nivel en el virreinato. Álzaga se esforzó por mostrarle la militarización sostenida con fondos y elementos que también provenían de los cabildos del interior. ${ }^{159}$ Allí, la tolerancia recíproca entre el cabildo alzaguista y el virrey Liniers comenzaba a agotarse hacia mediados de 1808, y se rompió definitivamente en enero de $1809,{ }^{160}$ sobre todo por los ataques de Álzaga desde el cabildo a las instituciones virreinales; más adelante profundizaremos este tema. Entonces ya se conocían la caída de Godoy (marzo de 1808) y las

155 Este intento de los cabildos de reasumir funciones que con Carlos III se habían reservado a virreyes y audiencias es un fenómeno extendido también a México. LUCENA GIRALDO, Manuel Naciones de rebeldes..., cit. p. 84.

156 Citado en LEVENE, Ricardo "La asonada...", cit. p. 470. En el mismo sentido se expresa Liniers en el oficio que libró al mismo cabildo en octubre de 1808: Mayo documental, III, doc. núm. 345, pp. 200 y ss. (Copia del oficio del virrey Santiago de Liniers al Cabildo de Buenos Aires..., 3 de octubre de 1808).

157 CMPC doc. núm. 6161, cit.

158 CABILDO DE CÓRDOBA, Actas capitulares..., cit., pp. 90 y 91 ("Y así estando: se mandó abrir un pliego de S.E. que en este día me entregó don Ambrosio Funes, y se encontró un oficio de 23 de octubre del presente año, en que se encarga no se moleste á dicho don Ambrosio en cosa alguna"; acta del cabildo de 10 de noviembre de 1809).

159 CMPC docs. números 6061, cit. y 6249, cit. Converso relativiza la importancia de estas ayudas. Lo cierto es que alcanzaron para que Funes fuera homenajeado por los capitulares de Buenos Aires, y premiado con elogiosas certificaciones de sus servicios a la causa que representaba. CONVERSO, Félix "El comercio de Córdoba...", cit.

160 LEVENE, Ricardo "La asonada...”, cit., p. 470. Por otro lado, el comisionado enviado por la Junta de Sevilla, el marino Joaquín Molina, daba cuenta de cómo la creación de "vales" toma de deuda del vecindario-, era uno de los temas que más enojaba al cabildo de la capital. Ver Mayo documental, VII, doc. núm. 844, p. 135 (Oficio del comisionado de la Junta Central, Joaquín Molina..., 10 de enero de 1809). 
abdicaciones de Bayona (mayo de 1808);161 esto, más la creación de las juntas peninsulares, abría la puerta para cuestionar la legitimidad de los funcionarios cuyas fuentes de autoridad, es decir de quienes habían recibido sus nombramientos, habían sucumbido. ${ }^{162}$

Durante la segunda mitad de 1808 y hasta noviembre de 1809, Funes seguía en Buenos Aires y compartía a través de Álzaga vínculos con la elite capitular montevideana;"163 Ambrosio ensalzaba al "intrepido, é incorruptible Elío", 164 gobernador de la plaza, quien -con el apoyo de su elite capitular- había logrado formar junta en setiembre de 1808 e independizarse en los hechos de la capital del virreinato. De Elío decía que "la España protegida por Dios triunfará, y los buenos españoles que estamos en estas Américas con los americanos que somos una misma cosas, triunfaremos". ${ }^{165} \mathrm{Y}$ Álzaga era acusado de tener "prosélitos en el interior" para sus intentos fallidos de octubre de 1808 y enero de 1809 para formar junta en Buenos Aires. ${ }^{166}$ Como se ve, la diversidad de procedencias e intereses de los tres personajes no era un obstáculo para defender un núcleo compartido de convicciones sobre el corto y largo plazo del virreinato, una transitoria pero efectiva identidad política. Entre estos individuos circularán servicios y contraprestaciones: Funes reunía dinero para Buenos Aires, informaba a la corte sobre los logros de esa elite, ofrecía contactos en otras jurisdicciones, etc.; de Elío garantizaba tropas, dirección militar, amparo monárquico, incorruptibilidad; Álzaga ofrecía dinero propio, contactos en la corte, milicias, liderazgo indiscutido sobre los vecinos europeos, la protección del cabildo, etc. Todos estos intercambios estaban orientados a fortalecer una posición común: la de hacer notar los desmanes de los agentes de la corona enviados por la Metrópoli, y resaltar los beneficios de obtener cierta autonomía para las colonias, gobernadas por sus cabildos, en continuidad con

\footnotetext{
161 "en 14 de julio de 1808 llegó de España al puerto de Montevideo el bergantín Amigo Fiel, i en 25 la barca Santo Cristo del Grao, conduciendo este último buque la Real cédula de 10 de abril del propio año, que ordenaba la jura en aquellos dominios de nuestro Soberano el Señor don Fernando VII, i noticias más que suficientes para venir en conocimiento de los infames proyectos de Bonaparte..."; en TORRENTE, Mariano, Historiade la revolución..., cit., p. 18.

162 LUCENA GIRALDO, Manuel Naciones de rebeldes..., cit., p. 86

163 CANTER, Juan “Las sociedades secretas...", cit., p. 239.

164 CMPC doc. núm. 6249, cit.

165 Mayo documental, IX, doc. núm. 1055, p. 106 (Réplica de Francisco Javier de Elío a una nota de Francisco de Paula Sanz, 22 de junio de 1809). El resaltado es nuestro.

166 Mayo documental, VII, doc. núm. 811, p. 67 (Memorial anónimo sobre los acontecimientos del $1^{\circ}$ de enero..., 1809). Williams Álzaga muestra cómo circulaba especialmente por el Alto Perú la idea lanzada por Martín de Álzaga de una ruptura con la metrópoli por la caducidad de las autoridades regias. WILLIAMS ÁLZAGA, Enrique Dos revoluciones..., cit., pp. 183 y ss.
} 
el método con que se había logrado el rechazo del invasor inglés en la capital. ${ }^{167}$ Y por ello hubo borbónicos como de Elío, en Montevideo, que actuaron claramente con conceptos municipalistas.

El movimiento de los montevideanos de setiembre de 1808, alzados contra la autoridad virreinal del francés Liniers, era una experiencia muy cercana al modelo peninsular de juntas; se caracterizaba por creer que la vacancia del trono obligaba a crear espacios institucionales de excepción, ${ }^{168} \mathrm{y}$ que en las Indias se debía imitar a la Metrópoli:

“¿Monárquica nuestra constitución? ¿Esta acaso sentada y en posesión del trono de Castilla la sagrada Persona de Fernando? [...] ¿Monarquica una constitucion en cuyo lugar se ha subrogado una respectable, temida, y benerable democracia de los Varones masyntrepidos y fuertes del Imperio? $Y$ en esta repentina metamophosis, habrá delinquido esta parte del estado obrando á ymitacion del que le da la ley?". 169

Ambrosio percibe, contemporáneamente a de Elío, la excepcionalidad del momento:

"Asi como en la naturaleza los raros y graves fenómenos descubren raros, y grandes secretos, que al nuevo paso justifican los efectos extraños los principios ya conocidos, asi también sucede en el orden moral y político. No se dudara que á uno, y á otro pertenecen los acaecimientos de nuestra reconquista, y acciones ulteriores". ${ }^{170}$

Y también Ambrosio, como de Elío, presentaba los casos de las juntas en la península como ejemplares para programar el accionar en Indias: "Veanse los Papeles públicos de España, y se observara, que no hay motivo para impedir que aquí se establezca una Junta con presencia de los Sugetos que convenga, y diputados, ó Apoderados de los Pueblos bien instruidos."171 Álzaga, más propenso a la acción que a la teorización, en 1 de enero de 1809 hizo el intento de que una junta de cabildantes y otros notables de origen europeo ocuparan el

\footnotetext{
167 Ambrosio sería diputado a las cortes de todos los cabildos, a pedido del de Buenos Aires; CMPC doc. núm. 6249 cit.

168 "Las juntas nacieron con el indeleble sello sobre sí de su excepcionalidad: se trataba de instituciones de emergencia para una situación absolutamente anormal"; PORTILLO VALDÉS, José María Crisis atlántica..., cit., p. 55.

169 Mayo documental, III, doc. 353, pp. 220 y ss. (Copia de una Representación de la Junta de Gobierno de Montevideo contestando a la Real Provisión de la Audiencia de Buenos Aires..., 19 de octubre de 1808). El resaltado es nuestro.

$170 \quad$ CMPC doc. núm. 6252, cit.

171 CMPC doc. núm. 6252, cit.
} 
lugar de Liniers. ${ }^{172}$ Puede decirse que este es el nudo del relato que unía a de Elío, Funes y Álzaga: la creación de juntas en la península para repeler a los franceses; y garantizar la continuidad jurídica de la dinastía borbónica era una brecha abierta por los reinos y pueblos peninsulares que también debían aprovechar las provincias coloniales. Tal solución aportaba una ventaja: permitía desalojar del gobierno a los agentes de la corona designados por Godoy, entonces tenido por traidor a España en favor de Napoleón. ${ }^{173}$ Esta posición cobra fuerza cuando se afianza la Junta Central de Sevilla, que en su proclama de octubre de 1808, habló, refiriéndose a Godoy, de

“Una tiranía de veinte años, exercida por las manos más ineptas que jamas se conocieron, había puesto á nuestra Patria en la orilla del precipicio [...] En este momento crítico fue quando sacudiendo de repente el letargo en que yacíais, precipitasteis al Favorito [Godoy]de la cumbre del poder que usurpaba...". ${ }^{174}$

Como se ve en la admiración de Ambrosio por de Elío, la adhesión a la dinastía borbónica no era un demérito; sí lo era el hecho de que muchos funcionarios metropolitanos -Sobremonte, Rodríguez, Allende, Concha...quisieran anular a los cabildos en tiempos en que la monarquía temblaba. Funes, Álzaga, de Elio, con intenciones distintas, rechazaban a los funcionarios regios enviados desde la Metrópoli. Funes porque como patricio, había visto menguados su prestigio y su participación en los cargos coloniales; Álzaga, porque el pragmatismo de esos funcionarios los llevaba a enfrentar la interrupción del comercio con medidas comerciales que minaban aún más el monopolio; y de Elío, porque veía en los funcionarios metropolitanos a gente corrupta, habituada a ceder a las presiones y sugestiones de los criollos y europeos desafectos de cada plaza. Y los tres porque los consideraban persistencias indeseables de la época de Manuel Godoy. Este fue un momento de concordancia entre Funes, Álzaga y de Elío, en que los cabildos de Buenos Aires y Montevideo tenían una protagonismo inusitado por su participación en la reconquista y defensa 1806 y 1807, y por haber patrocinado con recursos de toda índole el desplazamiento de Sobremonte -el "monstruo godoysta", según Funes ${ }^{175}$ - y aunque el cabildo de Córdoba estaba domesticado por la maquinaria gubernamental monárquica de la intendencia, Ambrosio ganaba en el campo de lo simbólico, porque se les había anticipado en el intento de debilitar a Sobremonte cuando este era intendente de Córdoba y posteriormente

\footnotetext{
172 HALPERIN DONGHI, Tulio Revolución y guerra..., cit., pp. 265 y 266. También AGI, ESTADO,79, N.52

173 PORTILLO VALDÉS, José María Crisis atlántica..., cit., p. 54.

174 Mayo documental, IV, doc. núm. 460, p. 135 (Proclama de la Suprema Junta Gubernativa dirigida a la Nación española, 26 de octubre de 1808).

175 CMPC doc. núm. 6249, cit.
} 
a sus sucesores y aliados. Resumiendo, se puede decir que a esta confluencia de opiniones sobre la solución juntista para la situación del virreinato, de Elío la honró con una experiencia exitosa pero breve; Álzaga la procuró, pero fracasó; y Funes la plasmó en una ficción superadora que no pasó de los papeles en los que fue escrita: la confederación de cabildos del virreinato.

\section{El proyecto de Funes de 1808}

El borrador o copia personal de un escrito de Ambrosio Funes en el que plantea un cambio en las jerarquías institucionales de las provincias es el que mejor refleja esta confluencia de intereses de algunos europeos, americanos, monopolistas y marinos en un proyecto compartido, e importa, a la vez, la cumbre del pensamiento reformista de su autor. Su contenido es un proyecto gubernativo de notas confederales y su forma es la de una súplica al rey efectuada por el cabildo de la capital ante la Junta de Sevilla, pidiendo determinadas gracias y privilegios. ${ }^{176}$ El enfoque de lo que les corresponde al rey y a los súbditos es barroco: espera una recompensa por la actuación de las provincias del Río de la Plata contra los ingleses. ${ }^{177}$ Recogía las experiencias de Buenos Aires y Montevideo, más las coincidencias ideológicas enumeradas más arriba sobre cómo abordar la vacancia o, al menos, la incomunicación permanente con la Metrópoli. ${ }^{178}$ La propuesta de Funes fue la de remplazar en el gobierno de las intendencias de provincia coloniales a los enviados de la Metrópoli por sus cabildos: “El primer punto que se ha de tratar es remover de los Empleos Públicos á los malos, inútiles, sobremontistas, y ladrones, y públicos jugadores, y amancebados. El $2^{\circ}$ punto poner en aquellos hombres buenos, y estimados de los Pueblos" ${ }^{179}$ En la segunda frase está la superación del modelo de gobernadores intendentes designados por el gobierno metropolitano, por otro en que la participación de los representantes de los Pueblos, es decir de los vecinos institucionalizados en los cabildos, decidiría esas magistraturas provinciales. ${ }^{180}$

Retomemos lo dicho antes sobre que el encuadre legitimador para esta propuesta serían las juntas de España, constituidas desde mayo de 1808:

\footnotetext{
176 CMPC doc. núm. 6252, cit.

177 LUCENA GIRALDO, Manuel Naciones de rebeldes..., cit., p. 76. La respuesta de la Junta de Sevilla al cabildo de Buenos Aires, lo plantea así: "unos vasallos que tantos derechos han adquirido a la consideración y aprecio de su Soberano"; AHN, ESTADO, 55, E 44, cit.

${ }_{178}$ Para una aproximación a la presencia de ideas juntistas en el virreinato de México y otras jurisdicciones americanas, ver RODRÍGUEZ, Jaime La independencia de la América..., cit., p. 75-88.

179 CMPC doc. núm. 6252, cit. El resaltado es nuestro.

180 Es una época en la que de la metrópoli no llegan satisfacciones de ninguna índole para los reclamos de los americanos. PORTILLO VALDÉS, José María Crisis atlántica..., cit. p. 34.
} 
"Veanse la proclama de Valencia y se conocera qué deben hacer las Indias. Galicia es Pueblo: Andalucía, etc. y todas las Indias no son Pueblo?"181 Para Funes, no había duda de que el vínculo de las provincias virreinales con la Metrópoli había quedado homologado al de las provincias peninsulares, gracias a las victorias sobre los ingleses, por lo que la instalación de juntas no podía tildarse de desobediencia. ${ }^{182}$ La junta que decretó la cesantía de Sobremonte en febrero de 1807 no es un antecedente menor, anterior en más de un año a las juntas peninsulares. La gran diferencia es que las de 1808 en adelante tenían una función permanente; la de Buenos Aires fue excepcional y con un objetivo bien acotado: remover al virrey. Se pediría en ese escrito la ratificación de los actuado durante las invasiones, incluida la destitución de Sobremonte, y que se rediseñara la configuración institucional del virreinato con una interdependencia excluyente entre órganos municipales y el virrey; pretendía la casi extinción de las jurisdicciones intermedias metropolitanas como las de los gobernadores intendentes. En general, proponía que ante una nueva situación de emergencia -podría ser otra invasión inglesa, o una francesa o portuguesa, por ejemplo-,

"se faculte de nuevo [...] para resolver en un Cabildo abierto lo que delibere la pluralidad en todos sus artículos [...] Arreglado que sea el plan que adopte en lo político, gobernativo, y militar se propondrá el gose de todos los derechos, y medios conducentes a sostenerlo, teniendo a su disposision [el cabildo abierto de Buenos Aires] las armas, la marina, y el herario de todo el Virreynato con permiso de exigir de los mas de America lo que necesite". ${ }^{183}$

Lo que aquí solicitaba Ambrosio era que el mismo tipo de junta que desplazó a Sobremonte en febrero de 1807, fuera la que tomara las decisiones en tiempos de emergencia. ${ }^{184}$ Continúa con una declaración del más puro municipalismo como factor de legitimidad:

"Que se confiera al Exmo Cabildo [de Buenos Aires] la protección de los interiores, y [...] que tenga este mismo toda

\footnotetext{
$181 \quad$ CMPC doc. núm. 6252, cit.; el resaltado es nuestro.

182 Azcuy Ameghino resalta el rasgo subversivo que implicaba instituir una junta en un virreinato como el de Buenos Aires, por ser este una colonia; tal pretensión era inadmisible para la metrópoli, según este autor, por su intrínseco valor anticolonial. AZCUY AMEGHINO, Eduardo Nuestra gloriosa insurrección. La revolución anticolonial de Mayo de 1810. Trama política y documentos fundamentales, Imago Mundi, Buenos Aires, 2010, p. 3.

183 CMPC doc. núm. 6252, cit.

184 En España, "las juntas actuaron como un príncipe colectivo y no como un poder revolucionario"; esto encuadra a las juntas de De Elío y Funes como movidas por un ideal regenerativo y no revolucionario. PORTILLO VALDÉS, José María Crisis atlántica..., cit., p. 56.
} 
independencia para mandar e instituir sus ramos municipales, invertir sus fondos y no rendir cuenta de ellos, sino á S.M. con abolición de toda disposición en contrario: y que los demas Ayuntamientos logren el propio privilegio, sin mas subordinación que al de la Capital, á el qual pasaran sus cuentas en iguales términos". 185

Es un municipalismo con jerarquías internas: el cabildo de la capital es la cabeza del sistema y el puente hacia la corona. Otras partes del documentos piden al rey que los cabildos puedan participar de la designación de funcionarios en periodos normales, para lo que se preferirá a los americanos si estuvieren en igualdad de condiciones con los europeos (la sombra de la situación del deán en su lucha por ser obispo se proyecta sobre la agenda de Ambrosio); que a las residencias las realicen los cabildantes; que se restrinjan las milicias a un número que no produzca la quiebra del erario ni los riesgos de una insurrección; y la medida que tanto de Elío como Álzaga han reclamado con insistencia: la recuperación del monopolio, debilitado por Godoy y sus agentes en Indias:

"La extinsion del contrabando propende necesariamente á la prosperidad de la tierra: y asi que se faculte á este Cuerpo [cabildo de Buenos Aires] para que pueda armar uno ómas barcos que ayuden á celarlo a los que tenga el gobierno, quedando la parte de presa que le corresponda para propios de la Ciudad deducidas las expensas." 186

Los largos párrafos que la correspondencia entre Funes y Álzaga destina a la recuperación del monopolio, que, según sus conceptos, han debilitado los mandones metropolitanos para tener de donde cobrar sus salarios, quedó resumida en tres líneas en las que diseñó un sistema policial a cargo y en beneficio del cabildo. ${ }^{187}$ Se advierte cómo los derechos aduaneros de la corona no son cuestionados, sino reforzados. Y expuso Ambrosio su ambición de quedar favorecido, en este rediseño institucional, con los privilegios derivados del monopolio. ${ }^{188}$

Mientras Funes producía este documento en Buenos Aires -octubre de 1808-, el cabildo de Buenos Aires seguía mostrándose como intermediario de

\footnotetext{
185 CMPC doc. núm. 6252, cit.; el resaltado es nuestro. Letamendi, en carta a Funes de 16 de febrero de 1808, le asegura que el cabildo de Buenos Aires ya pidió a la corte se lo declare protector de todos los del interior; MARTINEZ PAZ, Enrique Papeles..., cit., p. 213; ver también lo ya dicho por VERDO, Geneviève “¿Soberanía del pueblo...?”, cit.

186 CMPC doc. núm. 6252, cit.

187 CMPC, doc. núm. 6249, cit.

188 SCHLEZ, Mariano Dios, rey y monopolio..., cit., pp. 64 y ss.
} 
las ciudades del interior, lo que mucho molestaba a Liniers. ${ }^{189}$ Aparecía gestionando donativos para la defensa de una eventual tercera invasión inglesa, o para la Metrópoli, o comunicando noticias de la guerra peninsular. Los puntos de encuentro entre el documento de Ambrosio y estos hechos son notables. ${ }^{190}$ En paralelo, las energías borbónicas seguían entrelazándose por iniciativa del virrey limeño. Abascal se escribía con las autoridades de Córdoba: con el intendente Concha, con su asesor Rodríguez, con el coronel Allende, lo cual insertaba a este grupo monárquico provinciano en el tablero del juego del virrey peruano y de la elite limeña. En Córdoba se recibían constantemente pliegos oficiales y cartas de arriba: de Abascal, de Nieto, de Goyeneche. ${ }^{191}$

El día 1 de enero de 1809, como anticipamos, luego de la elección de cabildantes en la capital, Álzaga se hizo notar con una revuelta; encabezó a la elite mezclada de muchos europeos y algunos pocos americanos para sacar a Liniers y formar una junta como la de Montevideo y las de la península. ${ }^{192}$ Resignado Liniers a perder su cargo, la intervención de Saavedra y de casi todos los comandantes de milicias criollas le devolvió el poder, en lo que constituyó la derrota del proyecto alzaguista de hacerse árbitro de la capital. ${ }^{193}$ Ambrosio describió esto, algunos meses después, como el fracaso de la oportunidad más clara de lograr su ansiada confederación de cabildos, encabezada por el de Buenos Aires. ${ }^{194}$ Álzaga fue confinado en el presidio de Patagones, de donde lo rescató de Elío; ambos permanecieron en Montevideo, en relación epistolar con Ambrosio, hasta que Cisneros le permitió volver a Álzaga en la segunda mitad de 1809. Esa mayoría nativa de las milicias, capitaneada por Saavedra, que salvó la permanencia de Liniers con su intervención, manifestó que el plan abortado era no solo el remplazo de la persona del virrey, sino la abolición del

189 HALPERIN DONGHI, Tulio Revolución y guerra..., cit., p. 145.

190 CMPC docs. núm. 5694, cit. y 5694 bis, citados; AHPC, Gobierno, Tomo 30, legajo 30, fs. 533.

191 ABASCAL, José Fernando Memoria de Gobierno..., cit., II; también GROUSSAC, Paul Santiago de Liniers..., cit., p. 312.

192 HALPERIN DONGHI, Tulio Revolución y guerra..., cit.; pp. 265 y 266. AGI, ESTADO,79, N.52

193 CMPC doc. núm. 6249, cit.; el acta donde consta que fueron los comandantes quienes impidieron la renuncia de Liniers en favor del cabildo de mayoría europea, en Mayo documental, VII, doc. núm. 826, p. 99 y ss. (Acta de la reunión de Ayuntamiento y Real Audiencia de la ciudad de Buenos Aires, en fecha $1^{\circ}$ de enero de 1809, a los efectos de designar una Junta...). La convicción de los cabildantes alzaguistas es la misma; Mayo documental, VII, doc. núm. 877, p. 251 y ss. (Oficio enviado por los apoderados de los capitulares de la ciudad de Buenos Aires, en el cual presentan sus quejas al rey, 25 de enero de 1809). HALPERIN DONGHI, Tulio Revolución y guerra..., cit., p. 154. La intervención de Saavedra marca la preponderancia de los americanos en las armas; HALPERIN DONGHI, Tulio “Del virreinato del Río de la Plata a la nación argentina”, en MINGUEZ, Víctor y CHUST, Manuel El imperio sublevado..., cit., pp. 277-288.

$194 \quad$ CMPC doc. núm. 6249, cit. 
cargo, y la constitución de un "Congreso o Senado, compuesto por los cabildantes de Buenos Aires y los diputados de cada Cabildo de las capitales de las provincias". ${ }^{195}$ Como se ve, la verosimilitud de este proyecto de Funes se fortalece con las opiniones de los enemigos de la camarilla que advertían sobre la trama que unía a cabildantes de la capital con algunos del interior. Saavedra, por ejemplo, hace notar que el objetivo político de Álzaga y de Elío incluía traer a los emigrados peninsulares por las guerras napoleónicas, en desmedro de los logros de los patricios. ${ }^{196}$

La llegada de Cisneros profundizó el proceso que se inició con la fracasada asonada de 1 de enero de 1809, por el cual la convergencia política de Funes, de Elio y Álzaga perdió las últimas chances de concretarse en un cambio institucional permanente. Fue en junio de 1809 cuando desembarcó en Montevideo, estableciéndose unas semanas allí para tantear la situación porteña. ${ }^{197}$ Se esperaba la inobediencia de Liniers y de las milicias al nombramiento de Cisneros. A fin de julio, tras negociaciones con el virrey saliente, pudo el entrante ser recibido como tal. Con el virrey acatado como funcionario legítimo, la junta de Montevideo perdía fuerza -su principal argumento había sido la traición de Liniers. ${ }^{198}$ El enfoque de Álzaga también se debilitaba porque el nuevo virrey no solo remplazaba al francés acusado de traidor, sino que como militar de carrera pondría en orden a las milicias criollas -que habían frustrado la asonada del 1 de enero-; ello reivindicaba a Álzaga. ${ }^{199}$ Además, Álzaga tuvo que avocarse a armar su defensa en el juicio que se le seguía por el alzamiento de enero de ese año; Cisneros, al permitir que el juicio siguiera su curso, neutralizó la actividad conspirativa de Álzaga por algún tiempo. Con Ambrosio pasó algo distinto, pero con resultados similares: convalidó el virrey unas elecciones realizadas en octubre por el cabildo de Córdoba, en que se eligió a Funes durante su ausencia para la terna de donde saldría el diputado del virreinato para la Junta Central. Esta reincorporación de Funes a los mecanismos institucionales que la situación de guerra legitimaba, se reforzó con una protección explícita del virrey, que le permitió volver a

\footnotetext{
195 Citado por WILLIAMS ÁLZAGA, Enrique Dos revoluciones..., cit., p. 180.

196 SAAVEDRA, Cornelio Memoria autógrafa..., cit., p. 43.

197 Mayo documental, IX, cit., doc. núm. 1080, p. 150 (Oficio de la Audiencia de Buenos Aires dirigido al virrey B.H. de Cisneros; representándole los efectos perjudiciales que causa su permanencia en la Banda Oriental, 19 de julio de 1809).

198 Mayo documental, IX, cit., doc. núm. 1094, p. 170 (Copia del oficio de Javier de Elío al virrey Baltasar Hidalgo de Cisneros; da cuenta de la alegría expresada por el vecindario ante la llegada de S.E. y señala que la Junta Provincial quedó disuelta, de acuerdo a lo ordenado por la Junta Central de España e Indias, 30 de julio de 1809).

199 Entre las instrucciones que la Junta de Sevilla dio a Cisneros para enfrentar la difícil situación en el Río de la Plata, estaba esta: “EL Virrey interin no tenga bastantes fuerzas veteranas debe usar la maior condescendencia, por que son los vecinos los que ha han de defender aquellas poseciones". Mayo documental, IX doc. núm. 1034, cit., p. 49.
} 
Córdoba sin ser molestado por los sobremontistas de Concha. ${ }^{200}$ A fines de 1809, Funes había vuelto a Córdoba y Álzaga a Buenos Aires; el primero como referente cercano al virrey Cisneros en la jurisdicción cordobesa, el segundo como reo enjuiciado en Buenos Aires. De Elío en agosto permanecía provisoriamente en Montevideo pero ya estaba designado sub-inspector general de las tropas en el virreinato, es decir el segundo en el mando militar después del virrey, con la intención de ser el respaldo que Cisneros necesitaba en caso de desacato en Buenos Aires; ${ }^{201}$ con ello, a pesar de estar descontento con las medidas que tomaba el nuevo virrey, quedó sumado también a la legalidad juntista, es decir al andamiaje gubernamental legitimado por la Junta Central de Sevilla., que había designado a Cisneros. ${ }^{202}$

Con tono nostálgico Funes repasaba en enero de 1810 los hechos que se dieron desde el juramento de Cisneros como virrey en julio de 1809; resaltaba los intereses comunes y posiciones conjuntas de varios capitulares de Buenos Aires, Córdoba y Montevideo. Funes defendía el ánimo destituyente de Álzaga y de Elío contra Liniers por ser un francés traidor; Elío lo mostró desde setiembre de 1808 con su Junta montevideana y Álzaga en enero de 1809, con el primer intento serio de formar junta en Buenos Aires. Funes los veía como servicios a la causa común: impedir que un francés se mantuviera al frente del virreinato con una legitimidad -la de la reconquista y la defensa- que en realidad la habían ganado los pueblos de Montevideo (verdadero reconquistador de Buenos Aires en 1806, no Liniers) y de Buenos Aires a la cabeza de su alcalde, y con una designación que la había promovido e impuesto el cabildo de la capital, no otra institución. ${ }^{203}$ Para Ambrosio, Liniers no era más que un mandatario de los poderes del pueblo de Buenos Aires, que lo había investido con autoridad a raíz de las invasiones inglesas, y que ese pueblo -el cabildo, por supuesto-, podía recuperar el cargo y dárselo a quien lo considerase. Para Funes, todo aquello no tenía otro fin que sostener los derechos del soberano cautivo. Por lo tanto, no podía aceptar que la junta montevideana y el motín de

200 Oficio de Cisneros al cabildo de Córdoba, fechado en 23 de octubre de 1809, y que Ambrosio trajo en mano; CABILDO DE CÓRDOBA, Actas capitulares..., cit. Ver también CMPC doc. núm. 6243 (Se refiere a las "persecuciones" que padecía del partido dominante y pide se mande suspender cualquiera resolución que solicitare contra él el gobierno de la intendencia, hasta que no fuera contestada la queja por su apoderado, 16 de octubre de 1809).

201 Mayo documental, IX, docs. números 1111, 1113 y 1117, pp. 220 (Oficio del Cabildo de la Plata al sub-inspector general Francisco Javier de Elio..., 10 de agosto de 1809), 221 (Carta de Jaime Zudáñez a Francisco Javier de Elio, 10 de agosto de 1809) y 225 (Carta de Pedro Vicente Cañete al subinspector general Francisco Javier de Elío..., 11 de agosto de 1809), respectivamente.

202 Mayo documental, IX, doc. núm. 1154, p. 287 (Oficio de Francisco Javier de Elio a Martín de Garay..., 24 de agosto de 1809).

203 CMPC doc. núm. 6249, cit. También WILLIAMS ÁLZAGA, Enrique Dos revoluciones..., cit., p. 160 
enero de 1809 en capital hubieran sido acciones contra la monarquía; por el contrario, eran un camino para su regeneración por la que estos reinos recibirían otro tipo de atención de la Metrópoli. Caminos desechados por culpa de la ineptitud y codicia de los oficiales americanos como Saavedra, sus compañeros y la chusma que los seguían, pensaba él, que erraron en apoyar a Liniers desechando la luminosa visión que compartía con Álzaga y de Elío. ${ }^{204}$

\section{Conclusiones}

Nos interesaba estudiar el periodo de 1805-1809 desde la perspectiva del ordenamiento jurídico-político vigente y no desde las valoraciones de la Revolución de Mayo; esto implica aceptar que hubo multiplicidad de proyectos políticos, algunos de los cuales convergieron en aquella y muchos otros, no. Para ello, partimos de la premisa de que las guerras europeas de inicios del siglo XIX, en especial desde 1805 en adelante, aumentaron la capacidad de maniobra de los cabildos del virreinato del Río de la Plata, pues la inestabilidad de los órganos peninsulares de gobierno revertía en más legitimidad jurídica y más capacidad política para tomar decisiones administrativas y políticas en ámbitos locales. La legitimidad y la autoridad de los cabildos eran indivisibles, y por ello se las veía como las células originarias de cualquier nuevo orden político. Seguir las trayectorias de algunos actores prominentes de la élite gobernante en estas circunstancias nos permitió dimensionar que esa generalización resultaba operativa para el Río de la Plata yque ellos actuaban integrados a los fenómenos políticos imperiales. Funes, Álzaga y de Elío tomaban decisiones a partir de las noticias y de los conceptos con que se manejaban los grupos metropolitanos y apreciaban las situaciones de sus contextos regionales con categorías que los enlazaban con aquellos. En el breve lapso de dos de años (1808-1809), construyeron una de las tantas identidades políticas que, desde dentro de la élite, se proyectaba sobre la totalidad del sistema monárquico: el municipalismo. Decimos que fue una identidad política porque, tomando ideas y reivindicaciones antiguas que circulaban por algunos sectores de la elite del virreinato, buscaba incidir eficazmente en la redefinición de los vínculos entre la monarquía y estas provincias coloniales restituyendo a los ayuntamientos las funciones de gobierno y mediación que las reformas de Carlos III habían diluido. Los cabildos reaparecían como articuladores dominantes de los diversos sectores que componían la sociedad colonial; proponía directamente el remplazo de los agentes de la corona, en algunos casos -como fue la destitución de Sobremonte o los golpes contra Liniers-; o la extinción de algunas instituciones, como se pretendió con las gobernaciones

$204 \quad$ CMPC doc. núm. 6218, cit. 
intendencias en los proyectos de Funes. Pero siempre respetando la continuidad de la sucesión dinástica de los Borbón. Los factores internacionales incidían en los ámbitos locales a través de estos agentes que tenían una posición tomada respecto de lo que debía hacerse en la Metrópoli y en cómo acompañar desde sus propios ámbitos los movimientos en la península, ya que advertían cuál era el peso de los acontecimientos en las provincias para el concierto imperial. El "anti-godoysmo" fue un factor aglutinante de voluntades en las provincias del virreinato, en particular durante el bienio central de nuestro estudio. Por eso, una herramienta indispensable para el grupo municipalista fue la adaptación de las juntas de notables y funcionarios que usó la Metrópoli, a los contextos regionales coloniales; con ello pretendía sostener la legitimidad y la legalidad de la monarquía hispana durante la ausencia de Fernando VII, con el fin de aumentar la legitimación de los ajustes políticos buscados sin afectar los derechos de la corona. En especial porque permitía dar por fenecidos los mandatos de los gobernantes coloniales enviados desde la península por haber desaparecido las autoridades peninsulares que los habían designados. La fuerza de las facciones que, por diverso motivo, se opusieron a la solución juntista hasta fines de 1809 (la de los funcionarios y vecinos borbónicos y la de los milicianos criollos, por ejemplo), frustró en Buenos Aires su instalación el 1 de enero e hizo desaparecer en Montevideo la que se instituyó en 1808. Las opciones frente a la vacancia regia eran muchas y ninguna hegemonizaba el sentido de la discusión; la velocidad y complejidad de los acontecimientos los obligaba a fijar objetivos a corto plazo. Los hechos que condicionaban el accionar local y regional en el virreinato escapaban a su control, pero producían adaptaciones e innovaciones con la llegada de cada noticia, cierta o falsa, al puerto de Buenos Aires. Ambrosio, en junio de 1810, en pleno duelo por los fracasos de su camarilla municipalista, se sumó a otra, más prometedora: la de los criollos militarizados de la capital, que antes se había opuesto a la idea de actuar a nombre de Fernando VII y que, en mayo de ese año, por los resultados de la guerra, estuvo decidida a arrogarse la representación de los pueblos del virreinato, en una junta como las de España, pero sin ningún mandón. 